\title{
Income and Non-Income Inequality in Post- Apartheid South Africa: What are the Drivers and Possible Policy Interventions?
}

\author{
Haroon Bhorat \\ Carlene van der Westhuizen \\ Toughedah Jacobs \\ Haroon.Bhorat@uct.ac.za
}

Development Policy Research Unit

DPRU Working Paper 09/138

August 2009

ISBN Number: 978-1-920055-74-5 


\section{Abstract}

South Africa has historically been ranked as one of the most unequal societies in the world and, while the country has experienced sustained positive economic growth since 1994, the impact of this growth on poverty, and particularly inequality, has been disappointing. Analysis using data from the 1995 and 2000 Income and Expenditure Surveys has found, for example, a significant increase in income inequality over the period and, further, that this increase in inequality eroded any significant poverty-reduction gains from higher economic growth. The release of the Income and Expenditure Survey 2005 enables us to examine changes in inequality over the decade between 1995 and 2005. Some preliminary analysis, however, shows a further increase in inequality over the second half of the period. This new result would possibly suggest that South Africa is now the most consistently unequal economy in the world. Critically, the persistent and increasing levels of inequality have been acting as a constraint ensuring that South Africa's economic growth results in significant declines in household poverty levels.

This study has two main objectives. Firstly, the study aims to identify the drivers of the reproduction of inequality in post-apartheid South Africa. The second objective is to examine what policy levers are available to help mitigate the impact of increased inequality in South Africa. Based on the identification of what is driving the increasing levels of inequality, appropriate policy interventions, including assessing the impact and sustainability of existing policies such as the increased provision of social grants, will be evaluated

We find that not only has income inequality remained high for the period under review, but it has also increased significantly between 1995 and 2005. Throughout the time period wage inequality has been the main contributor to the growing income inequality. For a more holistic representation of inequality, we consider the effect of increased public and private assets on non-income inequality. We find that there has been a universal decrease in non-income inequality in South Africa. We also find that the effect of income inequality has been to dampen growth, specifically pro-poor growth. While we found that social transfers have little effect on income inequality when we decomposed the various sources of income, when grant income is excluded as a source of income from total income we find that it is an extremely important supportive source of income and without it many households would experience negative income growth. 


\section{Acknowledgement}

Funding for this project was provided by the Second Economy Project, an initiative of the Presidency, situated within Trade and Industrial Policy Strategies (TIPS). The purpose of this project is to contribute to reducing poverty and inequality in South Africa by supporting the government to develop a Strategy for the Second Economy, as part of its Accelerated Shared Growth Initiative of South Africa (Asgi-SA).

Development Policy Research Unit

Tel: +2721650 5705

Fax: +27 216505711
Information about our Working Papers and other published titles are available on our website at: http://www.dpru.uct.ac.za/ 


\section{Table of Contents}

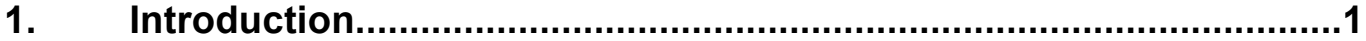

2. Shifts in Inequality in Post-Apartheid South Africa.........................

2.1 Data Sources and the Creation of the Income Variable.......................

2.2 Changes in Per Capita Income, 1995 - 2005....................................4

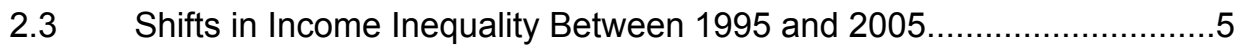

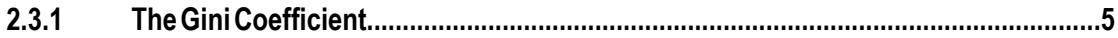

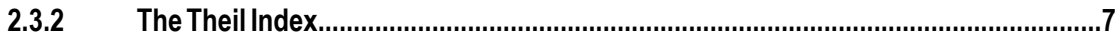

2.3.3 Results for South Africa: 1995-2005...................................................................

2.4 Decomposing Income Inequality in South Africa..............................15

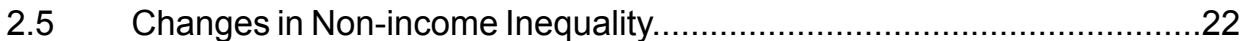

3. The Relationship between Economic Growth, Poverty and Inequal

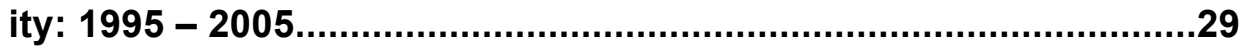

4. Policy Interventions to Mitigate the Impact of Rising Inequality in South Africa..............................................................................44

4.1 The Impact of the Increased Provision of Social Grants...................44

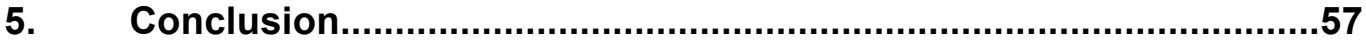

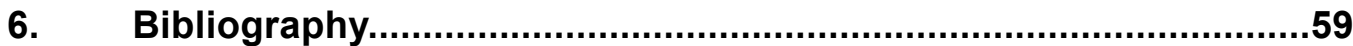

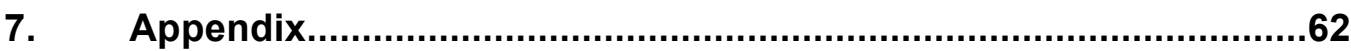




\section{Introduction}

South Africa has historically been ranked as one of the most unequal societies in the world, and while the country has experienced sustained positive economic growth since 1994, the impact of this growth on poverty, and particularly inequality, has been disappointing. Analysis using data from the 1995 and 2000 Income and Expenditure Surveys has found, for example, a significant increase in income inequality over the period and, further, that this increase in inequality eroded any significant poverty-reduction gains from higher economic growth. The release of the Income and Expenditure Survey 2005 has enabled us to now examine changes in inequality over the 10-year period between 1995 and 2005. Some preliminary analysis, however, shows a further increase in inequality over the second half of the period. This new result would possibly suggest that South Africa is now the most consistently unequal economy in the world. Critically, the persistent and increasing levels of inequality have been acting as a constraint to ensuring that South Africa's economic growth results in significant declines in household poverty levels.

This paper has two main objectives. The first objective is to provide a comprehensive overview of the changing levels of inequality in the post-apartheid South Africa and to identify the drivers of these changes. This also includes examining the relationship between economic growth, poverty and inequality over the period. The second objective is to evaluate the increased provision of social grants as a policy option to alleviate the impact of increasing inequality in South Africa.

Section 2 provides an overview of the changes in per capita income inequality between 1995 and 2005. Although private consumption expenditure is generally accepted as a more appropriate measure of welfare, we use income to calculate measures of inequality since we are particularly interested in the factors (that is, sources of income) that have been driving the changes in income inequality. In order to develop a comprehensive overview of welfare changes in the country over the period, we also consider the changes in non-income inequality as captured by the distribution of access to a range of basic services and privately owned assets in Section 3. While it is generally accepted that economic growth has a positive impact on poverty, rising income inequality may dampen the impact of economic growth on poverty reduction. Section 4 investigates this relationship between economic growth, poverty and inequality for the period between 1995 and 2005. 
The final section reviews the impact of Government's provision of social grants on income inequality. While the results from the decomposition of income inequality in Section 2 suggest that social grants as source of income did not serve to reduce income inequality, further analysis do show that social grant income made a significant contribution to total income across the income distribution, particularly in 2005. In this section we therefore exclude grant income from total income and recalculate some of the inequality measures as well as the growth incidence curves in order to estimate what the levels of inequality would have been in the absence of grant income. 


\section{Shifts in Inequality in Post-Apartheid South Africa}

\subsection{Data Sources and the Creation of the Income Variable}

Two main sources of data were utilised for this study, namely the 1995 Income and Expenditure Survey (1995 IES) and the 2005/06 Income and Expenditure Survey (2005/06 IES). These household surveys were conducted by Statistics South Africa with the specific aim of collecting information on the income and expenditure of South African households.

The methodologies of data collection as well as the questions themselves differ slightly between the two surveys and for the purposes of our analysis we carefully constructed total household income aggregates for 1995 and 2005. Only those sources of income that were included in both datasets were used to estimate total income. We were able to match the majority of income sources for the two years and only a very small share of income was excluded from the final total income aggregates with negligible implication for our inequality estimates.

For both years, total household income was derived as a simple sum of all the comparable sources of income. Total household income was then divided by household size to take into account the impact of the number of individuals living in a household on the distribution of income within that household. The structure (age and gender of the members) of a household also impacts on the relative consumption or income levels of the household members, with implications for the measurement of poverty and inequality. In order to account for this, equivalence scales are utilised, assigning adult equivalent values to the children in a household (for example, a child equaling 0.75 or 0.5 adults). At the time of writing, person level data (including age and gender) was not yet available for the 2005/06 IES, making it impossible to use adult equivalent scales. In addition, Leibbrandt and Woolard (2005) have shown that the choice of equivalence scale makes little difference to the ultimate identification of vulnerable households.

While empirical work on the distribution of welfare can be done using expenditure or income data, the international norm is to use private consumption expenditure as opposed to income when calculating changes in poverty and inequality. With the World Bank defining poverty as the "inability to attain a minimal standard of living" - measured in terms of basic consumption needs, it follows that consumption expenditure data is more appropriate. In addition, the recording of consumption expenditure is usually more reliable and stable than income, 
especially amongst the poor (see Woolard \& Leibbrandt in Leibbrandt et al, 2001 for a detailed discussion). The specific aim of our analysis, however, is to identify the sources of income that have been driving the changes in inequality between 1995 and 2005 and we therefore proceed by first calculating the changes in income inequality over the period. In order to maintain consistency and facilitate the identification of specifically the impact of the provision of social grant income on income inequality, all estimates in this paper are calculated using per capita income.

\subsection{Changes in Per Capita Income, 1995 - 2005}

Table 1 provides an overview of the changes in individual per capita income between 1995 and 2005. All individuals, irrespective of race and the gender of the household head, experienced statistically significant increases in their nominal per capita household incomes between 1995 and 2005. At the aggregate level, nominal incomes more than doubled over the decade, with slightly lower growth experienced by African and Asian individuals.

Table 1: Changes in Per Capita Income by Race and Gender of Household Head, 1995 - 2005

\begin{tabular}{lcccccc}
\hline & \multicolumn{2}{c}{ Nominal } & \multicolumn{2}{c}{ Real } & \multicolumn{2}{c}{$\%$ Change } \\
\hline African & 1995 & $\mathbf{2 0 0 5}$ & $\mathbf{1 9 9 5}$ & $\mathbf{2 0 0 5}$ & Nominal & Real \\
Coloured & $5,144.68$ & $9,156.97$ & $7,105.91$ & $6,979.40$ & $77.99 \%$ & $-1.78 \%^{*}$ \\
Asian & $7,075.80$ & $17,335.16$ & $9,773.20$ & $13,212.78$ & $144.99 \%$ & $35.19 \%$ \\
White & $16,688.50$ & $32,415.41$ & $23,050.42$ & $24,706.87$ & $94.24 \%$ & $7.19 \%^{*}$ \\
Male Headed & $35,907.41$ & $91,420.28$ & $49,595.87$ & $69,680.09$ & $154.60 \%$ & $40.50 \%$ \\
Female Headed & $10,866.91$ & $24,433.57$ & $15,009.54$ & $18,623.15$ & $124.84 \%$ & $24.08 \%$ \\
Total & $4,774.59$ & $9,797.55$ & $6,594.74$ & $7,467.64$ & $105.20 \%$ & $13.24 \%^{*}$ \\
\hline
\end{tabular}

Source: $\quad$ Statistics South Africa (1995 \& 2005) and Own Calculations

Notes: 1 . The population in 1995 has been weighted according to the 1996 Census, while the population in 2005 has been weighted according to the 2001 Census. In both datasets, the population has been weighted by the household weight multiplied by the household size.

2. And asterisk $\left({ }^{*}\right)$ denotes that the change is not statistically significant at the 95 percent level. 
When the impact of inflation over the period is taken into account, the increase in real income at the aggregate level was only about 11.5 percent. White individuals, followed by Coloured individuals, experienced the largest increases in their real income, with increases of 40.5 and 35.2 percent respectively. Individuals living in male headed households experienced an increase of about 24 percent in their real incomes over the decade. However, in real terms, Africans, Asians and individuals living in households headed by females, did not experience any statistically significant change in their incomes over the period.

While the evidence presented above suggests that, at least in nominal terms, all South Africans experienced growth in their incomes between 1995 and 2005, the following section considers the changes in the distribution of income that accompanied that growth in per capita income.

\subsection{Shifts in Income Inequality Between 1995 and 2005}

The South African society has historically been characterised by high levels of income inequality and in the following section we provide an overview of the changes in income inequality between 1995 and 2005. Three standard measures are utilised, namely the Gini coefficient, the Lorenz Curve and the Theil index. These measures are complementary to each other as they are able to describe the extent and nature of inequality in different ways.

\subsubsection{The Gini Coefficient}

The Gini coefficient is one of the most commonly used measures of inequality since it is relatively easy to understand and interpret. The crucial drawback of the Gini coefficient is that it is not additively decomposable. This means that while it is easy to interpret, the overall Gini coefficient is not a sum or average of the respective subgroup Gini coefficients. Simply put, it is not possible to combine the various provincial Gini coefficients, for example, to obtain the national Gini coefficient. In fact, it is quite possible that the national Gini coefficient can be greater than or less than all nine provincial coefficients.

The Gini coefficient is derived from the Lorenz Curve, which is a graphical depiction of income distribution. Figure 1 presents an example of a Lorenz Curve, indicated by the solid curved line, which is constructed with the cumulative percentage of the population, arranged from poorest to the richest, on the horizontal axis, and the cumulative percentage of income received by each cumulative percentage of population on the vertical axis. The Lorenz Curve is then a graphical representation of the relationship between the 
cumulative percentage of income and the cumulative percentage of (ordered) population. Thus, in practice, one would be able to say the poorest 20 percent of the population earn, for example, five percent of total income, while the poorest 40 percent of the population earn, say, 15 percent of the income. The Lorenz Curve will start at the origin, the point where zero percent of the population receives zero percent of the income, and will end at the point where 100 percent of the population enjoys 100 percent of the income.

The more unequal a society, the smaller the proportion of income that will accrue to the poorest segment of the population and, accordingly, the lower the Lorenz Curve will be on the figure. At its most extreme - perfect inequality - one person receives all the income and all other individuals receive nothing and the Lorenz Curve will therefore proceed horizontally from the origin, remaining on the horizontal axis until the last person is added to the cumulative shares, which will result in the Curve going up almost vertically to the point where 100 percent of the population receives 100 percent of the income (forming, in other words, a reversed ' $\mathrm{L}$ ' shape). Conversely, a situation of perfect equality will see each person receiving the same income and, thus, the poorest 20 percent of the population will receive 20 percent of the income, the poorest 40 percent of the population will receive 40 percent of the income and so on. In this case, the Lorenz Curve will form a straight diagonal line from the origin to the point where 100 percent of the population receives 100 percent of the income (illustrated by the broken line in the figure). This line is known as the line of perfect equality. Any Lorenz Curve (except for perfect equality) will therefore lie below the diagonal.

\section{Figure 1: An Example Lorenz Curve}

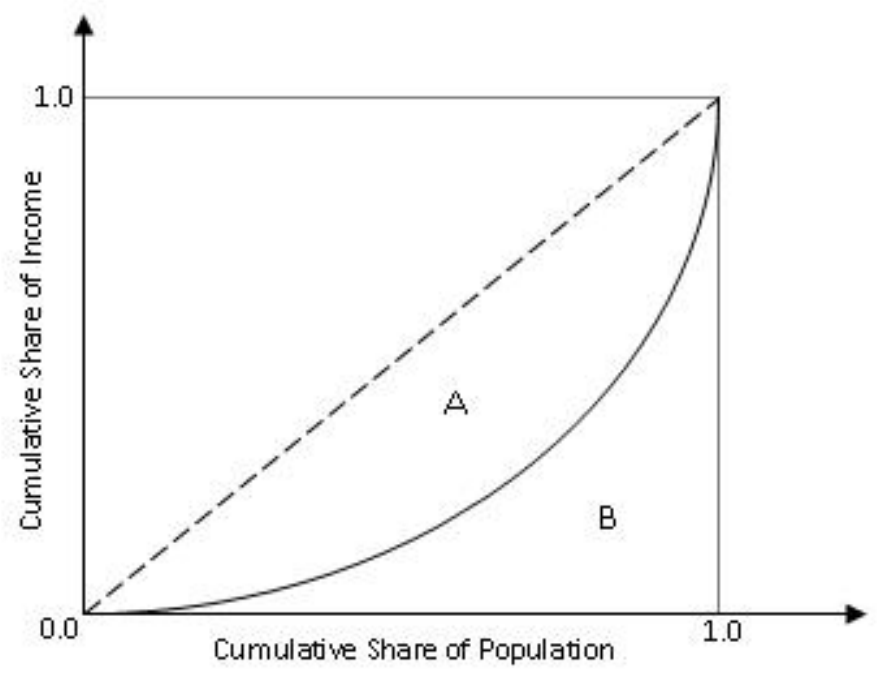


The Gini coefficient is a measure of the extent of the deviation of the observed Lorenz Curve from the line of perfect equality and is calculated by relating the area between the Lorenz Curve and the line of perfect equality (graphically represented by area $A$ ) to the total area below the line of perfect equality (graphically represented by the sum of area A and area B), expressed as a proportion.

Simply put, the Gini coefficient equals $A /(A+B)$, with possible values ranging from zero to one (Sen 1997; Fields 2001). A value of zero implies that area A equals zero, i.e. that the Lorenz Curve lies exactly on the line of perfect equality, and thus a Gini coefficient of zero indicates perfect equality within a society. A value of one implies that area $B$ equals zero, i.e. that the Lorenz Curve follows the horizontal axis and then turns almost vertical (forming a reversed 'L' shape), representing a situation of perfect inequality. The higher the Gini coefficient is, therefore, the higher the level of inequality.

\subsubsection{The Theil Index}

In contrast to the Gini coefficient, the Theil index is neither intuitive nor easy to interpret. However, its one advantage is that it has the ability to decompose overall inequality into a proportion originating between subgroups and a proportion originating within subgroups. Thus, for example, overall inequality can be decomposed by race, with a certain proportion of overall inequality being explained by inequality between the race groups, and the remainder being explained by within race groups.

The Theil-T statistic is defined as $T=T_{B}+\sum q_{i} T_{i}$, where $T_{i}$ measures the inequality within the ith group, $q_{i}$ is the proportion of income accruing to the ith group, and $T_{B}$ measures the inequality between the different subgroups. Even though $T_{B}$ and $T$ are calculated similarly, $T_{B}$ assumes that all the incomes within a group are equal (Leibbrandt et al 2001).

\subsubsection{Results for South Africa: 1995-2005}

The section below presents the changes in income inequality, using per capita household income, for South Africa between 1995 and 2005. The results suggest that all South Africans, irrespective of race, location, or the gender of the household head, experienced an increase in income inequality over the decade.

For the South African economy as a whole, the Gini coefficient increased from 0.64 in 1995 to 0.72 in 2005 . This result is disturbing for at least two reasons. Firstly, international experience has shown that measures of income inequality do not alter significantly over time in either 
direction. It takes large shifts in economic growth for example, to change an economy's income distribution or a very particular pattern of growth (Kanbur 2005). Secondly, the result is disconcerting within the context of South Africa being historically ranked as the most unequal society in the world with Brazil. This new result suggests that South Africa is now the most consistently unequal society in the world.

Table 2: Inequality Shifts by Race: Gini Coefficients for South Africa, 1995 and 2005

\begin{tabular}{lll} 
& 1995 & 2005 \\
\hline African & 0.56 & 0.61 \\
Coloured & 0.49 & 0.59 \\
Asian & 0.46 & 0.56 \\
White & 0.44 & 0.51 \\
\hline Total & $\mathbf{0 . 6 4}$ & $\mathbf{0 . 7 2}$ \\
\hline
\end{tabular}

Source: $\quad$ Statistics South Africa (1995 and 2008) and Own Calculations

Notes: 1. The changes in the values of the Gini coefficients between 1995 and 2005 are "in bold" when the results are statistically significant at the 95 percent level.

2. The population in 1995 has been weighted according to the 1996 Census, while the population in 2005 has been weighted according to the 2001 Census. In both datasets, the population has been weighted by the household weight multiplied by the household size.

The data by race confirms that, with the exception of Asian individuals, all population groups experienced a statistically significant increase in income inequality over the period as measured by the Gini coefficients. While the Coloured population experienced the largest relative increase in inequality, with their Gini coefficient increasing from 0.49 in 1995 to 0.59 in 2005, the African population displayed the highest level of inequality in both years. In 1995, the relatively higher levels of inequality experienced by Africans are statistically significant, but due to the large increase in Coloured inequality, the Gini coefficients for these two groups are not statistically significantly different from each other in 2005. In other words, by 2005 these two groups experienced relatively similar levels of inequality, with the White population continuing to experience relatively lower levels of inequality.

The Lorenz Curve presented in Figure 2 visually confirms the changes in inequality experienced by South Africa between 1995 and 2005. The Lorenz Curve also confirms the robustness of the changes in inequality as measured by the Gini coefficient. 
Figure 2: Lorenz Curve for South Africa, 1995 and 2005

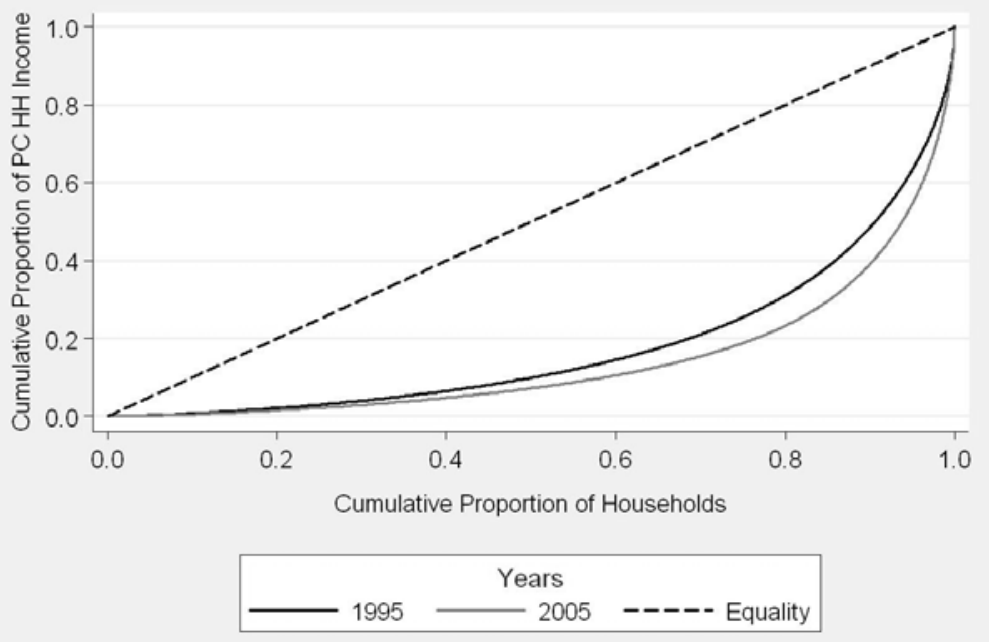

Source: $\quad$ Statistics South Africa (1995 and 2008) and Own Calculations

Notes: $1 . \quad$ The changes in the values of the Gini coefficients between 1995 and 2005 are statistically significant at the 95 percent level.

2. The population in 1995 has been weighted according to the 1996 Census, while the population in 2005 has been weighted according to the 2001 Census. In both datasets, the population has been weighted by the household weight multiplied by the household size.

In 1995, for example, the Lorenz Curve shows that the "poorest" 80 percent of the population only received about 30 percent of the income. By 2005, the share of income received by the same cumulative share of the population declined to just more than 20 percent. Put differently, by 2005 , the "richest" 20 percent of South Africans received almost 80 percent of income while in 1995 , this segment of the population received about 70 percent of income.

Figure 3 presents the Lorenz Curves for Africans and Whites for 1995 and 2005. Again, these visually confirm the increasing levels of inequality experienced by both population groups between 1995 and 2005. For both White and African individuals, the 2005 curves are positioned further away from the "equality" curve than the 1995 curves. 
Figure 3: Lorenz Curves for Africans and Whites for South Africa, 1995 and 2005

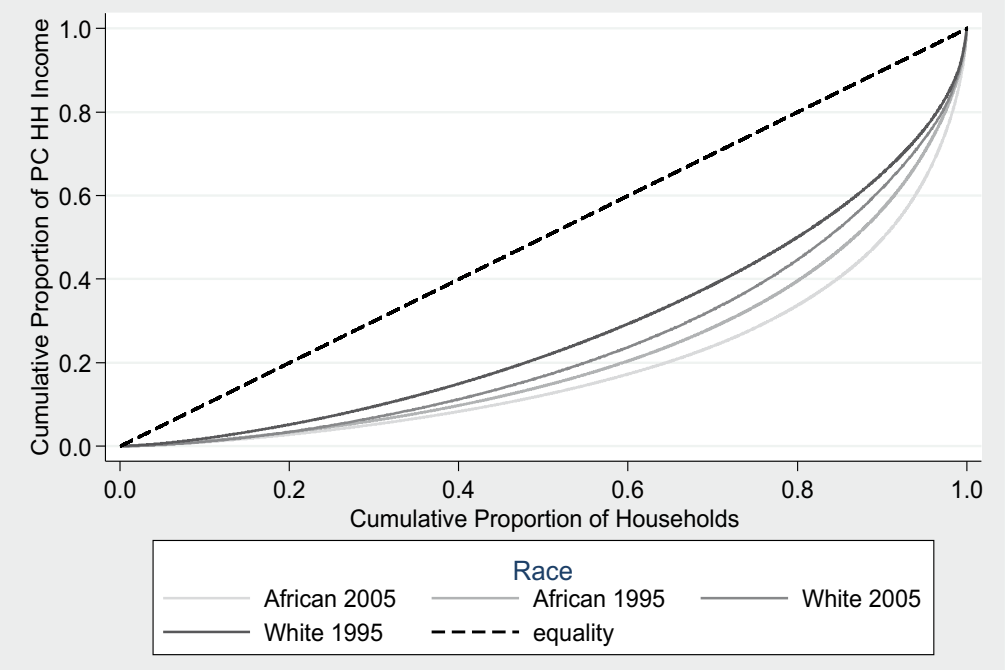

Source: $\quad$ Statistics South Africa (1995 and 2008) and Own Calculations

Notes: $1 . \quad$ The changes in the values of the Gini coefficients between 1995 and 2005 are statistically significant at the 95 percent level.

2. The population in 1995 has been weighted according to the 1996 Census, while the population in 2005 has been weighted according to the 2001 Census. In both datasets, the population has been weighted by the household weight multiplied by the household size.

The Lorenz Curves also confirm that in both years, Africans experienced relatively higher levels of inequality than the White population. For example, the position of the Lorenz Curves indicates that in 2005, the "bottom" 80 percent of the White population received approximately 45 percent of the income in this population group. In 2005, the "poorest" 80 percent of the African population only received about 30 percent of the total income accumulated by this population group.

Table 3 presents the Theil index by race for 1995 and 2005. Historically, as a result of the policies implemented during apartheid, the high levels of inequality in the country have been driven by inequality between race groups (See Leibbrandt et al 2001). More recent studies, either using data from the 1996 and 2001 Census or the 1995 and 2000 IES, have found an increase in the contribution of within-group inequality to total inequality, driven to a large extent by the increase in inequality amongst Africans. The rising inequality amongst Africans has been driven by high African unemployment on the one hand and increasing incomes at the very top of the distribution on the other (see Leibbrandt et al 2005 and Hoogeveen \& Özler 2006). 
The Theil index presented here, however, suggest a reversal of the trends observed by the studies cited above. Specifically, the results in Table 3 suggest that the contribution of withingroup inequality has declined in the decade between 1995 and 2005, while the between-group inequality component has gained in importance.

Table 3: Theil Index by Race for South Africa, 1995-2005

\begin{tabular}{lcccc}
\cline { 2 - 5 } By Race & \multicolumn{2}{c}{1995} & \multicolumn{2}{c}{2005} \\
\hline Total Inequality (Theil-T) & 0.87 & $100 \%$ & 1.14 & $100 \%$ \\
Within & 0.50 & $57.4 \%$ & 0.63 & $55.6 \%$ \\
Between & 0.37 & $42.6 \%$ & 0.51 & $44.4 \%$ \\
\hline
\end{tabular}

Source: $\quad$ Statistics South Africa (1995 and 2008) and Own Calculations

Notes: We are unable to calculate t-statistics and confidence intervals for the Theil Index and therefore unable to comment on the statistical significance of the changes between 1995 and 2005 in the Theil Index.

This result presented in Table 3 is critical, since it suggests that it is primarily income differences between race groups, rather than those within, that have been driving South Africa's growing inequality levels. Put differently, this suggests that the contrasting income gains made across race groups has been the key determinant of rising aggregate income inequality in the South African economy. In addition, this suggests that the past view that the rise in income inequality has been mostly caused by the growing African affluence relative to the increasing unemployment within the African population has to be reconsidered.

In addition to race and location, gender is also considered a key marker of vulnerability in the South African context. Table 4 presents the changes in income inequality according to the gender of the head of the household. Again, all South Africans, irrespective of the gender of the head of the household they resided in, experienced increasing levels of income inequality over the period.

Table 4: Inequality Shifts by Gender Head of Household: Gini Coefficients for 1995 - 2005

\begin{tabular}{lll}
\cline { 2 - 3 } & 1995 & 2005 \\
\hline Male head of Household & 0.63 & 0.70 \\
Female head of Household & 0.59 & 0.68 \\
Overall & 0.64 & 0.72 \\
\hline
\end{tabular}

Source: $\quad$ Statistics South Africa (1995 and 2008) and Own Calculations

Notes: 1. The changes in the values of the Gini coefficients between 1995 and 2005 are "in bold" when the results are statistically significant at the 95 percent level.

2. The population in 1995 has been weighted according to the 1996 Census, while the population in 2005 has been weighted according to the 2001 Census. In both datasets, the population has been weighted by the household weight multiplied by the household size. 
The Gini coefficient for individuals living in households headed by males increased from 0.63 to 0.70 , while the Gini coefficient for those living in female-headed households increased from 0.59 in 1995 to 0.68 in 2005. In both years, however, the difference in the Gini coefficients according to the gender of the household is not statistically significant. In other words, the gender of the household head did not impact significantly on the levels of inequality experienced by the household members.

The Lorenz Curve according to the gender of the household head visually confirms the results presented in Table 4.

Figure 4: Lorenz Curve for Gender of Household head South Africa, 1995 - 2005

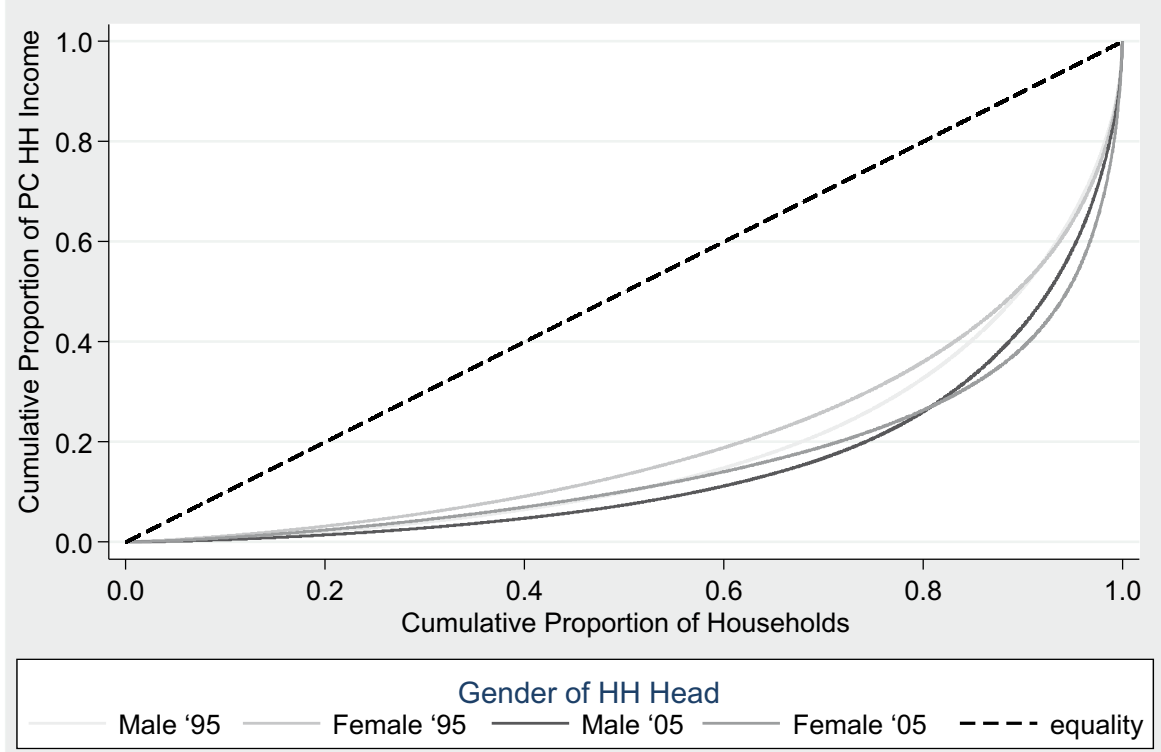

Source: $\quad$ Statistics South Africa (1995 and 2008) and Own Calculations

Notes: 1. The changes in the values of the Gini coefficients between 1995 and 2005 are statistically significant at the 95 percent level with the exception of the Rural population.

2. The population in 1995 has been weighted according to the 1996 Census, while the population in 2005 has been weighted according to the 2001 Census. In both datasets, the population has been weighted by the household weight multiplied by the household size.

The Lorenz Curves in Figure 4 clearly show that both male- and female-headed households experienced increases in their levels of income inequality, with both 2005 curves lying further away from the "line of equality" than the 1995 curves. In both years, however, the curves for the two cohorts lie relatively close to each other and even cross each other, illustrating that there were very little difference in the levels of inequality experienced by these two groups. The Theil Index, presented in Appendix 4, confirms this result. In both years, more than ninety percent of total inequality was driven by inequality within these two groups, with the decline in 
the contribution of this component almost negligible. In other words, inequality between male and female headed households contributed very little to total inequality in both years.

Table 5 presents the Gini coefficients by location, specifically by urban and rural area. Individuals living in urban areas experienced a statistically significant increase in income inequality, with their Gini coefficient increasing from 0.59 to 0.69 between 1995 and 2005. The rural population did not experience any statistically significant change in income inequality over the same period, with their Gini coefficient remaining relatively stable (0.62 in 1995 and 0.60 in 2005). The difference between the Gini coefficients for the rural and urban population groups is only statistically significant in 2005 , driven by the increase in urban inequality. This means that by 2005 , individuals living in urban areas were experiencing significantly higher levels of inequality than their rural counterparts.

Table 5: Gini Coefficient by Location, 1995-2005

\begin{tabular}{lll}
\cline { 2 - 3 } Settlement Type & 1995 & 2005 \\
\hline Urban & 0.59 & 0.69 \\
Rural & 0.62 & 0.60 \\
Overall & 0.64 & 0.72 \\
\hline
\end{tabular}

Source: $\quad$ Statistics South Africa (1995 and 2008) and Own Calculations

Notes: 1. The changes in the values of the Gini coefficients between 1995 and 2005 are "in bold" when the results are statistically significant at the 95 percent level.

2. The population in 1995 has been weighted according to the 1996 Census, while the population in 2005 has been weighted according to the 2001 Census. In both datasets, the population has been weighted by the household weight multiplied by the household size.

The rise in income inequality for urban areas is another crucial result, and it appears as if income inequality in urban areas has become another significant shaper of aggregate income inequality. A major contributing factor to the increase in income inequality in urban areas is migration, in the form of both rural-urban migration and cross-border (that is, across provincial borders) migration, or more simply put, from weak economies to relatively stronger economies. Limited employment and income generating opportunities force migrants to migrate from rural areas to urban areas or from poorer to relatively better-off provinces. Most migrants have little formal skills and once in urban areas, are restricted to low paying jobs or are compelled to work in the insecure informal sector (Posel \& Casale 2006). Growing inequality, especially in the better performing (and mostly urban) provinces such as Gauteng and the Western Cape, could thus also be caused by the stretching of the wage income distribution. 
Figure 5: Lorenz Curve by Location for South Africa, 1995-2005

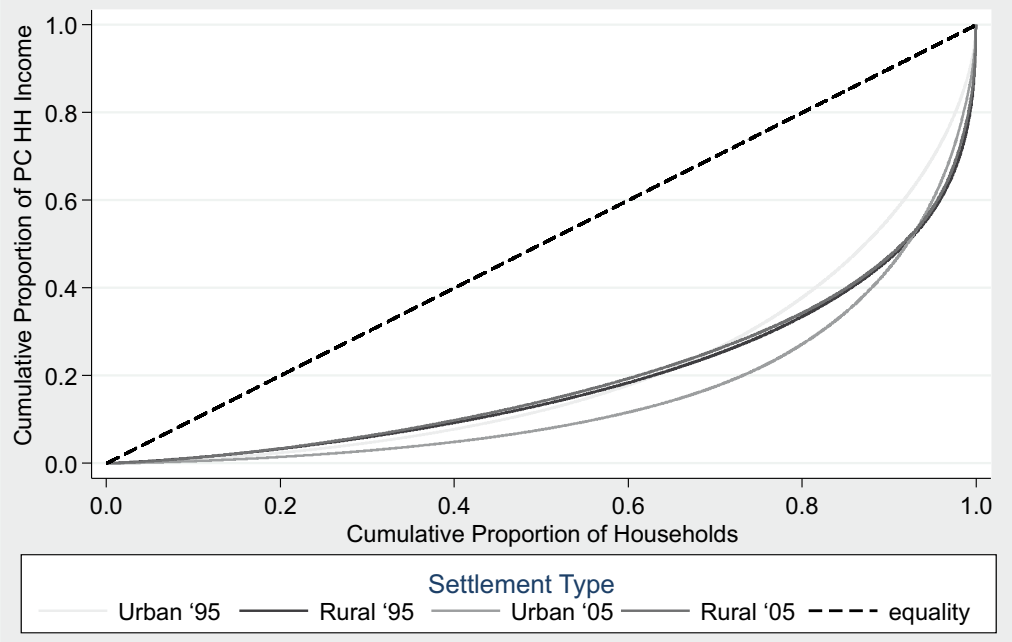

Source: Statistics South Africa (1995 and 2008) and Own Calculations

Notes: 1. The changes in the values of the Gini coefficients between 1995 and 2005 are statistically significant at the 95 percent level with the exception of the Rural population.

2. The population in 1995 has been weighted according to the 1996 Census, while the population in 2005 has been weighted according to the 2001 Census. In both datasets, the population has been weighted by the household weight multiplied by the household size.

The Lorenz Curves in Figure 5 very clearly show that income inequality increased significantly in urban areas between 1995 and 2005. The positions of the rural Lorenz curves confirm that inequality in rural areas remained relatively unchanged. In addition, the curves clearly illustrate that while the levels of urban inequality in 1995 appear to be lower than the levels of rural inequality in both years, for the most part the 2005 urban Lorenz Curve lies outside both the rural curves, confirming the relatively higher levels of urban inequality in 2005.

The Theil index by location reveals that income inequality is driven predominantly by the income inequality within the urban and rural population, and not between individuals living in urban and rural areas respectively. There was only a slight increase in the contribution of between group inequality between 1995 and 2005, driven by the slightly higher levels of inequality in urban areas relative to rural areas. 
Table 6: Theil Index by Location for South Africa, 1995-2005

\begin{tabular}{llllll} 
By Location & \multicolumn{3}{c}{2005} \\
\hline \multicolumn{1}{c}{1995} & & 1.14 & \\
\hline All (total) & 0.87 & & & 0.98 & $85.8 \%$ \\
Within & 0.75 & & $86.7 \%$ & 0.16 & $16.6 \%$ \\
Between & 0.11 & & $13.3 \%$ & 0 \\
\hline
\end{tabular}

Source: $\quad$ Statistics South Africa (1995 and 2008) and Own Calculations

Notes: We are unable to calculate t-statistics and confidence intervals for the Theil Index and therefore unable to comment on the statistical significance of the changes between 1995 and 2005 in the Theil Index.

The changes in income inequality for the nine provinces in South Africa as measured by the Gini coefficient can be found in Appendix 2. Six of the nine provinces experienced statistically significant increases in income inequality between 1995 and 2005. The Western Cape, the Eastern Cape, the Northern Cape, KwaZulu-Natal, Gauteng and Mpumalanga experienced increases in their Gini coefficients of between four and twelve percentage points. (The Free State, North West and Limpopo provinces did not experience any statistically significant change in their levels of inequality.) The Theil index by province (see Appendix 3) shows that inequality within the provinces has been the key driver of total inequality over the period, with the contribution of within-group inequality remaining relatively unchanged at around 90 percent.

\subsection{Decomposing Income Inequality in South Africa}

The data presented in the section above provides a general overview of the changes in income inequality in South Africa. While the estimates for income inequality are, as noted above, startlingly high, we attempt below a standard decomposition of the Gini coefficient by income sources, using the methodology developed by Lerman and Yitzhaki (1985). In terms of the focus here, we are particularly interested in how the different income sources manifest as drivers of income inequality in South Africa. We also decompose the Gini coefficient by income sources for the four race groups, and the results can be found in Appendix 7 .

The sources of income that are utilised in the disaggregation of the Gini coefficient are wage income, income derived from self employment, state transfers (or state grants), capital income and private pensions. All other income sources are combined into the 'other' category. From a policy perspective, the roles of state transfers and income from self-employment are of a particular interest to us, since we expect that these two sources of income have the most potential to decrease the high levels of inequality. 
Inequality in the distribution of total income as measured by the Gini coefficient $(G)$ can be decomposed as:

$$
G=\sum_{k=1}^{K} S_{k} \cdot G_{k} \cdot R_{k}
$$

where $S_{k}$ represents the importance (percent share) of the income source $k$ in total income, $G k$ is the Gini coefficient of the distribution of income source $k$ for all individuals, and $R_{k}$ is the Gini correlation of income from source $k$ with total income. The three components, $S_{k}, G_{k}$ and $R_{k}$, enter multiplicatively into the equation and the product $S_{k} G_{k} R_{k}$ is the contribution of the income source $k$ to the Gini coefficient calculated using total income. The size of the contribution of a given income source $k$ to total income inequality therefore depends on the value of the product $S_{k} G_{k} R_{k}$. The only component that can possibly have a negative value is $R_{k}$ (ranging between negative and positive one), indicating a possible negative correlation between the income from source $k$ and total income. Such an income source would then contribute towards lowering overall income inequality for the group.

Decomposing the Gini coefficient using this method means that we are looking at the relationship between $R_{k}, S_{k}$ and $G_{k}$, and considering the cumulative effect of these three variables on the Gini coefficient for the various income sources. For example, we see below that capital income and income from private pensions contribute very little to overall inequality even though both sources of income have a high positive correlation with total income. These two income sources also display high levels of inequality, but since these two sources of income constitute only a small share of total income, their overall contributions to income inequality are negligible. Wage income on the other hand is the main contributor to the high income inequality found within South Africa since wages are (1) highly correlated with the Gini coefficient; (2) wage inequality is high as yielded by the high Gini coefficient; and (3) its share of total income is significant. It is therefore expected that it would be one of the main contributors to and the drivers of total income inequality.

Table 7 presents the results for the Gini decomposition by income sources for South Africa for 1995 and 2005. Wage income is the most dominant source of income at the aggregate level as well as for all race groups in both years. In 1995 wage income constituted 60 percent of total income and by 2005 , this share has increased to 70 percent of total income. 
Table 7: Decomposition of Disposable Income by Income Source, South Africa, 1995 - 2005

\begin{tabular}{|c|c|c|c|c|c|}
\hline & 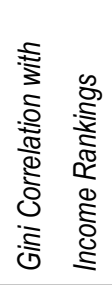 & 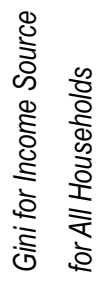 & 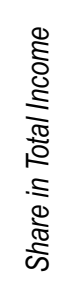 & 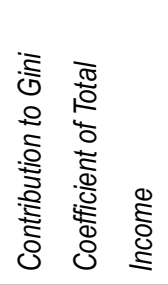 & 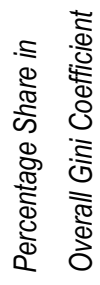 \\
\hline Income Source (1995) & $R_{k}$ & $G_{k}$ & $S_{k}$ & $S_{k} G_{k} R_{k}$ & Share \\
\hline Wage income & 0.90 & 0.72 & 0.61 & 0.39 & $60.9 \%$ \\
\hline Self-employment & 0.89 & 0.98 & 0.15 & 0.13 & $19.7 \%$ \\
\hline Grants & -0.08 & 0.84 & 0.04 & 0.00 & $-0.4 \%$ \\
\hline Capital & 0.85 & 0.99 & 0.01 & 0.01 & $1.5 \%$ \\
\hline Private pensions & 0.73 & 0.98 & 0.03 & 0.02 & $3.7 \%$ \\
\hline Other & 0.69 & 0.81 & 0.17 & 0.09 & $14.6 \%$ \\
\hline Gini & & & & 0.64 & $100.0 \%$ \\
\hline \multicolumn{6}{|l|}{ Income Source (2005) } \\
\hline Wage income & 0.95 & 0.81 & 0.70 & 0.54 & $75.6 \%$ \\
\hline Self-employment & 0.83 & 0.97 & 0.11 & 0.09 & $11.9 \%$ \\
\hline Grants & 0.00 & 0.69 & 0.07 & 0.00 & $0.0 \%$ \\
\hline Capital & 0.88 & 1.00 & 0.01 & 0.01 & $1.5 \%$ \\
\hline Private pensions & 0.76 & 0.98 & 0.03 & 0.02 & $3.0 \%$ \\
\hline Other & 0.73 & 0.89 & 0.09 & 0.06 & $7.9 \%$ \\
\hline Gini & & & & 0.72 & $100.0 \%$ \\
\hline
\end{tabular}

Sources: $\quad$ Statistics South Africa 1995, 2005 and Own Calculations

Notes: 1 . The population in 1995 has been weighted according to the 1996 Census, while the population in 2005 has been weighted according to the 2001 Census. In both datasets, the population has been weighted by the household weight multiplied by the household size.

Since wage income contributes significantly to total income, it is expected that it would also be the income source, which contributes most significantly to income inequality and the results presented above confirm this. Wage income has increased its contribution to income inequality by 14.7 percentage points over the period, from 61 percent in 1995 to almost 76 percent in 2006.

Figure 6 provides further evidence of the significant contribution of wage income to income inequality. This graph shows the contribution of the four main sources of income to total income in each income decile for 1995 and 2005. It is evident that the share of wage income in total income is relatively higher for those in the top four deciles, while this proportion decreases considerably in the bottom income deciles. This result highlights the role the labour 
market plays as a driver of income inequality. On the one hand, highly skilled workers are rewarded with high wages, while lower and unskilled workers are either poorly paid or unable to find employment - thus accounting for the relatively small contribution of wage income to total income in the bottom income deciles.

Figure 6: Changes in contribution of the different sources of income, 1995 - 2005

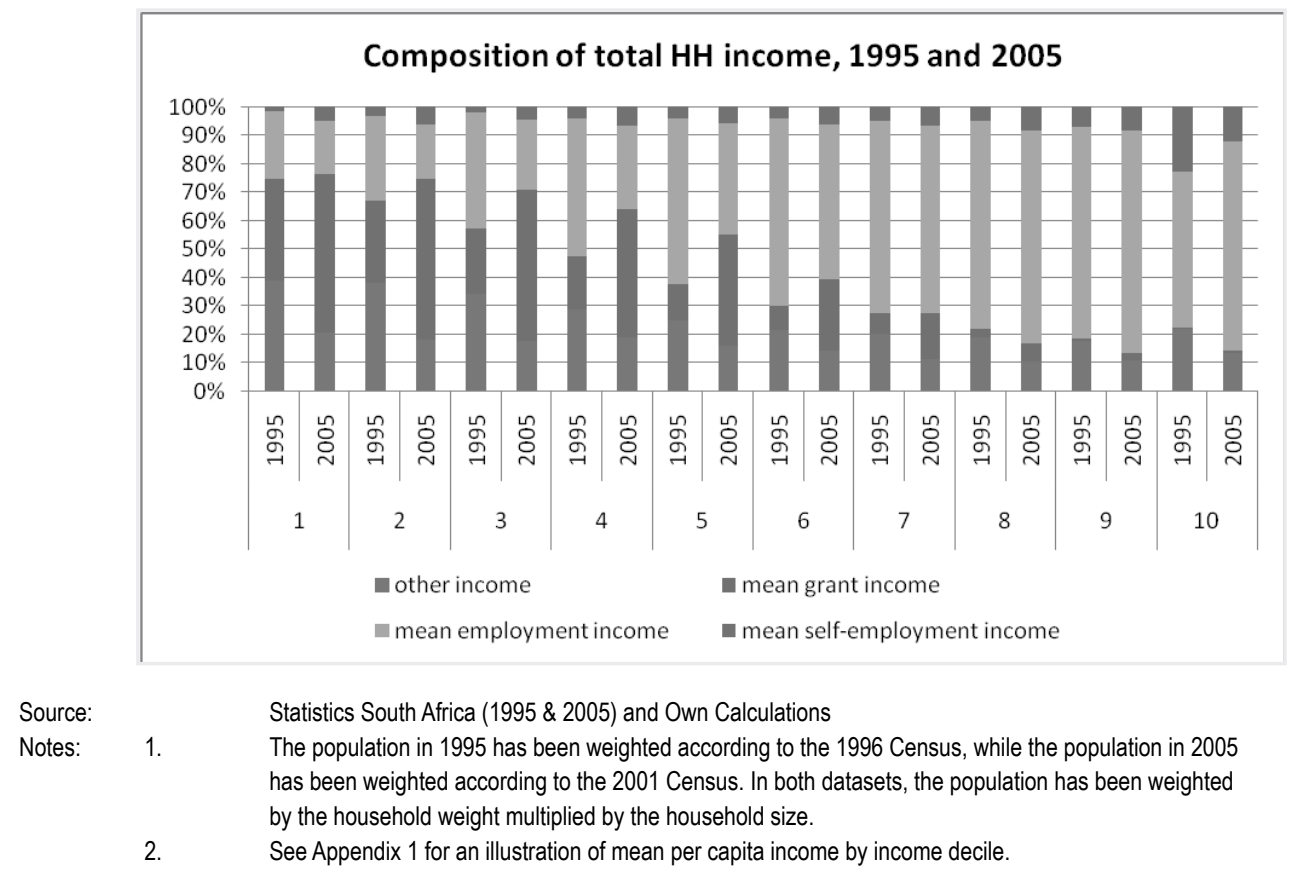

The results for grant income in the Gini decomposition are unexpected. Given the methodology used to decompose the Gini coefficient, the expectation was that the Gini correlation of grant income with total income would be negative, that is, that only those at the very bottom of the income distribution (with no income from other sources) would receive grant income. This would mean that social grants would be a source of income that would decrease income inequality. We see that in 1995, grant income did serve to decrease total income inequality, but with a magnitude of less than half a percent. In 2005, however, grant income did not serve to either increase or decrease income inequality. In fact, its contribution to total inequality as measured by the Gini coefficient was zero.

The explanation for this result lies in the relationship between grant income and total income. The general assumption is that grants are only targeted at households at the bottom of the income distribution (that is, the poorest of the poor), and the result would be a negative or inverse relationship between grant income and total income. Figure 6, however, shows that 
in 2005, households in the middle-income deciles also received grant income and that this income source made a significant contribution to total income in these income deciles. (In fact, grant income accounted for almost 20 percent of the total income of households in the seventh income decile and even households in the top three deciles received some grant income. As a result, the relationship between grant income and total income is positive. The Gini decomposition therefore captures the fact that social grants are provided to households across most of the income distribution and the provision of grant income thus appears to be distribution neutral.

While the result above may suggest that the provision of social grants has not been as welltargeted as previously thought, it is important to remember that even in the seventh income decile, mean per capita incomes can be relatively low. In fact, in 2005, the annual mean per capita income in the seventh income decile was only around R8 800 and in the same year, the value of the Old Age Pension was R780 a month (National Treasury, 2005) or R9 360 a year which is more than the mean income in the seventh income decile.

Income from self-employment is the second highest contributing source of income to income inequality. The contribution of this income source to total inequality has, however, decreased considerably, from 19.7 percent in 1995 to 11.9 percent in 2005 . This trend can partly be explained by the fact that in 1995 only individuals in the tenth income decile earned a substantial share of income from self-employment (more than 20 percent). By 2005, the relative contribution of income from self-employment to total income has declined by almost 50 percent in the tenth decile, while all other deciles experienced an increase in the share of total income attributed to self-employment. In fact, it appears as if the average contribution of this income source was between five and ten percent in the bottom seven deciles, with a slightly larger share in the top three deciles. This relatively larger share in the top deciles accounted for the positive contribution of this source to total income inequality.

While entering into self-employment is often proposed as an opportunity for the unemployed to gain employment and earn income, it is difficult to draw any meaningful conclusions from the result presented above. Income from self-employment (including informal sector employment) was captured differently in the two surveys and the increased income from self-employment in the lower deciles may to a large extent reflect the improved capturing of income from these activities. It is therefore difficult to accurately deduce from the above that increased levels of self-employment accounted for the decline in the contribution of this income source to total 
income inequality. Finally, it is also clear that income from self employment did not serve to actually reduce income inequality in 2005 .

The Gini coefficient was also decomposed by income sources for the four race groups. The results can be found as Appendix 7.

Even though all race groups experienced an increase in the contribution of wage income to total income, the composition of total income differs slightly by race. Wage income contributed 64 percent to total income for the African population in 1995 and 68 percent in 2005 . The contribution of wage income to total income increased more significantly for White individuals relative to the other race groups, from 55 percent in 1995 to 70 percent in 2005.

The results for the races, especially for the African population, are very similar to the aggregate results. Again, we find that wage income is the driver of income inequality for all race groups, and its contribution to income inequality has increased between 1995 and 2005 . It plays a particularly important role in explaining the income inequality for the African and Coloured population group, with wage income contributing more than 80 percent to income inequality. While the sources of income that drive inequality are the same, their importance in explaining income inequality differs across the race groups. Grant income is distributional neutral for the African and White population, while it has a slight dampening effect on income inequality within Coloured population. In other words, the provision of social grants did manage to reduce income inequality very slightly for Coloured individuals in both years.

\section{Wage Income as a Driver of Income Inequality}

The above analysis of income inequality has made it clear that wage income is the leading contributing factor to income inequality. In addition, its contribution to income inequality has increased between 1995 and 2005. Hence it is unmistakable that wages remain the factor explaining income inequality, but its importance in explaining income inequality has been further entrenched over the years. If we can understand what factors are driving wage income, and which portion of the distribution of households have access to wage income, then it may then be possible to improve our understanding of income inequality.

Figure 7 shows the percentage of the population in South Africa that had access to wage income and how this was distributed across the total per capita income deciles in 1995 and 2005. The share of individuals with access to wage income increased over the period in the bottom two deciles and in the top four deciles. In the third to the sixth deciles, the proportion of 
individuals with access to wage income was slightly lower in 2005 than in 1995. Regardless of these changes, in both years relatively larger proportions of the population had access to wage income as you move along the income distribution.

The increase in individuals with access to wage income in the top income deciles alludes to the distorted character of the post-apartheid South African labour market. The labour market is typically characterised by a mismatch in the demand and supply of labour, with a continuing increase in the demand for skilled labour, while there is a vast pool of unskilled labour available. Since 1995, there has also been a general increase in labour force participation rates, but insufficient employment opportunities have been created for these new labour market entrants (Bhorat \& Goga 2008) and (Bhorat \& Oosthuizen 2006). The result was increasing levels of unemployment over the period.

The structural change in the South African economy, that is, a shift away from the primary and secondary sectors to the tertiary sector has driven the increased demand for skilled labour. As a result, the relative wages of skilled workers have increased over 1995 to 2005 period. Skilled workers (such as Managers and Professionals) are concentrated in households at the top end of the income distribution, with these workers generally more employable in the current South African labour market and more able to command relatively higher wages. A relatively small portion of the South African population is skilled, and it is this skill premium which causes the skewed wage distribution, ultimately driving the high levels of income inequality in South Africa.

Figure 7: Percentage of Population with Access to Wage Income, 1995 - 2005

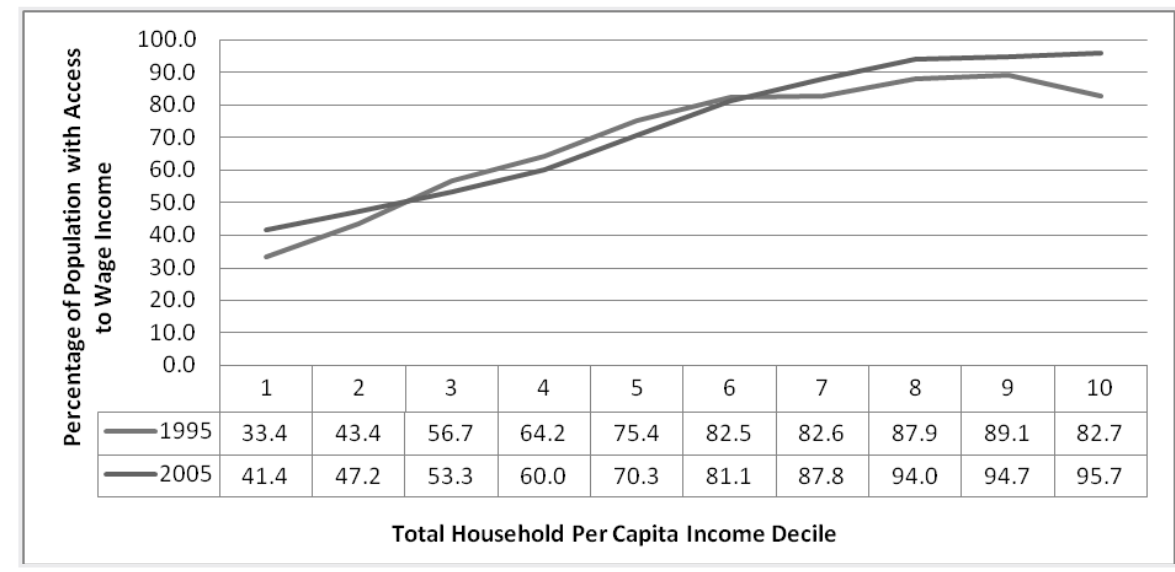

Sources: $\quad$ Statistics South Africa 1995 and 2008; Own Calculations

Notes: Population weights are not available for the 2005 dataset. The population has been weighted by the household weight multiplied by the household size to obtain the population weights. Both sets of weights are 2001 Census weights. 
Since wage inequality is the most important contributing factor to income inequality, a more detailed analysis into wage inequality is warranted. Given the limitations of the IES, a more detailed analysis of wage distribution using these datasets is not possible. We draw on existing evidence from studies using other datasets to explain the inequality found within wages. Bhorat and Goga (2008) investigate wage inequality using the 2001 and 2006 Labour Force Survey of South Africa. Wage inequality is first measured by estimating the Gini coefficient for real wages and secondly by analysing the differences in the distribution of real wages. While they find that the Gini coefficient has remained relatively stable between 2001 and 2006, their analysis of changes in the wage differential shows that there has been a decrease in the overall wage inequality.

Bhorat and Goga (2008) analyse the changes in the 90-10, 90-50 and 50-10 wage differentials between 2001 and 2006. The 90-10 differential represents the differences in wages for those at the 90th and 10th percentile of the wage distribution, the 90-50 differential explains the differential in wages for those at the 90th and 50th percentile and the 50-10 differential explains the differential in wages between the 50th and 10th percentile. The 90-10 wage differential is thus a proxy for 'overall wage inequality', and it is also the sum of the difference in inequality in the top and bottom-half of the distribution. Ultimately they find that overall wage inequality has decreased over the period, but the 50-10 and 90-50 differentials display opposing trends. They show that while the 90-10 and 50-10 wage differential decreased, it was the increasing 90-50 wage differential that contributed the most to wage inequality. The decrease in inequality at the lower end of the distribution, that is, the 50-10 wage differential, could be explained by the introduction of minimum wage legislation. The increasing 90-50 wage differential is explained by two forces, the first is the rising premium paid to highly skilled workers accompanied by the stagnating wages for skilled workers.

Wage inequality in the latter part of post-apartheid South Africa is therefore explained by increasing wages for skilled workers and particularly the gap between the wages of those at the top $\left(90^{\text {th }}\right.$ percentile $)$ and middle $\left(50^{\text {th }}\right.$ percentile $)$ of the distribution.

\subsection{Changes in Non-income Inequality}

The evidence presented in the previous section has shown that South Africa's levels of income inequality have increased between 1995 and 2005. With a few minor exceptions, this trend was observed to be invariant with respect to race, location and the gender of the household head. We also found that the increase in income inequality was driven by increasing levels of 
wage inequality. Importantly, however, it would be imprudent to ignore other indicators of living standards, such as access to basic services and private assets. Access to basic services is an important measure of living standards as it has a direct impact on the quality of life of the population (Leibbrandt et al 2006).

To measure changes in non-income inequality we construct an index of basic services consisting of public and private assets. The public assets included in the index are: the type of dwelling (formal, informal, or traditional); type of roof (brick, tile, corrugated, thatch, asbestos or other); type of wall material (low or high quality), source of water (piped, public, surface or borehole), source of energy for lighting (electricity, paraffin, or candle) and type of toilet (flush/chemical, pit, pit-VIP, bucket or none). The private assets included in the index are: telecommunications (cellular telephones and landline), vehicle, radio and television. The 1995 and 2005 IES datasets used in our estimation of income inequality do not contain sufficient information on access to public and private assets. We therefore chose to utilise the 1993 South African Integrated Household Survey from the Project for Living Standards and Development (PSLSD) and the 2005 General Households Survey (GHS) in our estimations of changes in non-income inequality. Both these surveys are nationally representative household surveys and we present the changes in non-income welfare by households and not individuals.

Aggregate non-income inequality has decreased significantly between 1993 and 2005 and this decline in non-income inequality stands in direct contrast to the substantial increase in income inequality between 1995 and 2005. The improvement in the levels of non-income inequality is largely the result of the increased access to public services (see Bhorat et al 2007) for a more detailed discussion), especially in the lower household expenditure deciles.

Table 8: Gini Coefficient for Non-income Inequality by Race for South Africa, 1993-2005

\begin{tabular}{lll} 
& 1993 & 2005 \\
\hline African & 0.26 & 0.21 \\
Coloured & 0.09 & 0.08 \\
Asian & 0.03 & 0.05 \\
White & 0.03 & 0.03 \\
Overall & $\mathbf{0 . 2 5}$ & $\mathbf{0 . 1 9}$ \\
\hline
\end{tabular}

Source: $\quad$ PSLSD 1993 (SALDRU), GHS 2005 (Statistics South Africa); Own Calculations

Notes: The changes in the values of the Gini coefficients between 1993 and 2005 are "in bold" when the results are statistically significant the 95 percent level.

The African population also experienced a significant decrease in non-income inequality. Importantly, non-income inequality for the African population remains higher than non- 
income inequality at the aggregate level and for the other race groups. (The changes in nonincome inequality for the other race groups are not statistically significant.) While the African population has benefitted significantly from the increase in the provision of basic services since 1994, a large share of the African population remains without access to water, electricity, housing and sanitation. Addressing these major backlogs in the delivery of basic services will serve to further reduce non-income inequality in the country.

Figure 8: Lorenz Curve for Non-income Inequality, 1995-2005

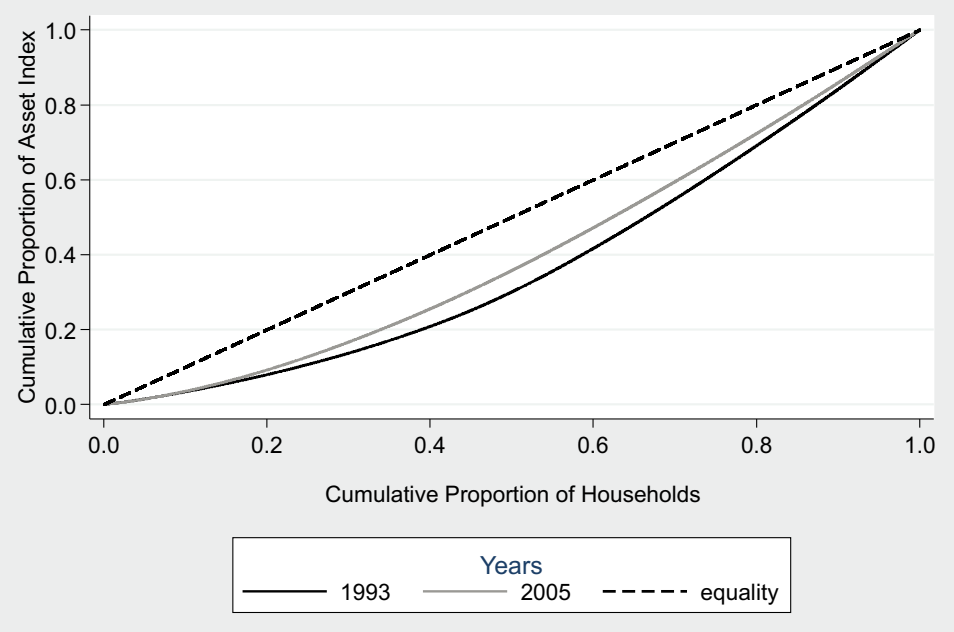

Source: PSLSD 1993 (SALDRU), GHS 2005 (Statistics South Africa); Own Calculations

The Lorenz Curve in Figure 8 visually confirms that aggregate non-income inequality has decreased substantially between 1993 and 2005. For example, in 1993, 60 percent of the population had access to or owned 40 percent of the total assets and services in the economy, and by 2005 , this increased to approximately 50 percent.

The results of the Theil index calculated using per capita income, showed an increase in between group inequality when race is considered. In contrast, when the Theil index is calculated using our basic services index, the results suggest that non-income inequality has increased within race groups.

Table 9: Theil Index for Non-income Inequality by Race for South Africa, 1993-2005

\begin{tabular}{lllll} 
By Race & 1993 & Share & 2005 & Share \\
\hline Within & 0.06262 & $60.1 \%$ & 0.05139 & $79.2 \%$ \\
Between & 0.04155 & $39.9 \%$ & 0.01347 & $20.8 \%$ \\
Overall & 0.10417 & & 0.06486 & \\
\hline
\end{tabular}

Source: PSLSD 1993 (SALDRU), GHS 2005 (Statistics South Africa); Own Calculations 
In other words, it is the differences in access to basic services and private assets within race groups that drive non-income inequality. As highlighted above, the post-apartheid government has made significant progress in the delivery of basic services to households. In addition, government's delivery of public assets between 1993 and 2005 has generally been pro-poor, both in the absolute and relative sense. Households in the bottom expenditure deciles experienced greater increases in access to public assets than those at the top of the distribution (Leibbrandt et al 2006 and Bhorat et al 2007). However, while households at the top of the distribution generally have access to all services and assets, those at the bottom are still lagging behind. The Theil index in particular captures the fact that within the African population group, a large number of households still do not have access to basic services.

Table 10 shows that, in line with the aggregate result, non-income inequality decreased significantly for both male- and female-headed households.

Table 10: Gini Coefficient by Gender of Household Head for Non-income Inequality by Race for South Africa, 1993-2005

\begin{tabular}{lll} 
By Gender of Household Head & 1993 & 2005 \\
\hline Male & 0.22 & 0.18 \\
Female & 0.27 & 0.21 \\
Overall & 0.25 & 0.19 \\
\hline
\end{tabular}

Source: $\quad$ PSLSD 1993 (SALDRU), GHS 2005 (Statistics South Africa); Own Calculations

Notes: The changes in the values of the Gini coefficients between 1993 and 2005 are "in bold" when the results are statistically significant at the 95 percent level.

While female-headed households experienced the largest relative decrease in non-income inequality between 1993 and 2005, non-income inequality remained relatively higher for female-headed households than at the aggregate and for male-headed households in 2005. This result again captures the relatively higher levels of vulnerability experienced by females and households headed by females in South Africa.

The Lorenz Curves confirm the decline in non-income inequality for both male- and femaleheaded households. Both the 2005 curves are lying closer to the "equality" line than the 1993 curves. In addition, the difference in non-income inequality between male and female-headed households has decreased significantly between 1993 and 2005 as a result of the relatively larger decline in non-income inequality experienced by female-headed households. In 1993, for example, 60 percent of female-headed households had access to less than 40 percent of assets and services, while in 2005, these households had access to approximately 45 percent of assets and services. The decline in non-income inequality for male-headed households was 
slightly smaller. In 1993, 60 percent of female-headed households had access to about 45 percent of assets and services, while in 2005, 60 percent of male-headed households had access to less than 50 percent of assets and services.

Figure 9: Lorenz Curve by Gender of Household Head for Non-income Inequality by Race for South Africa, 1993-2005

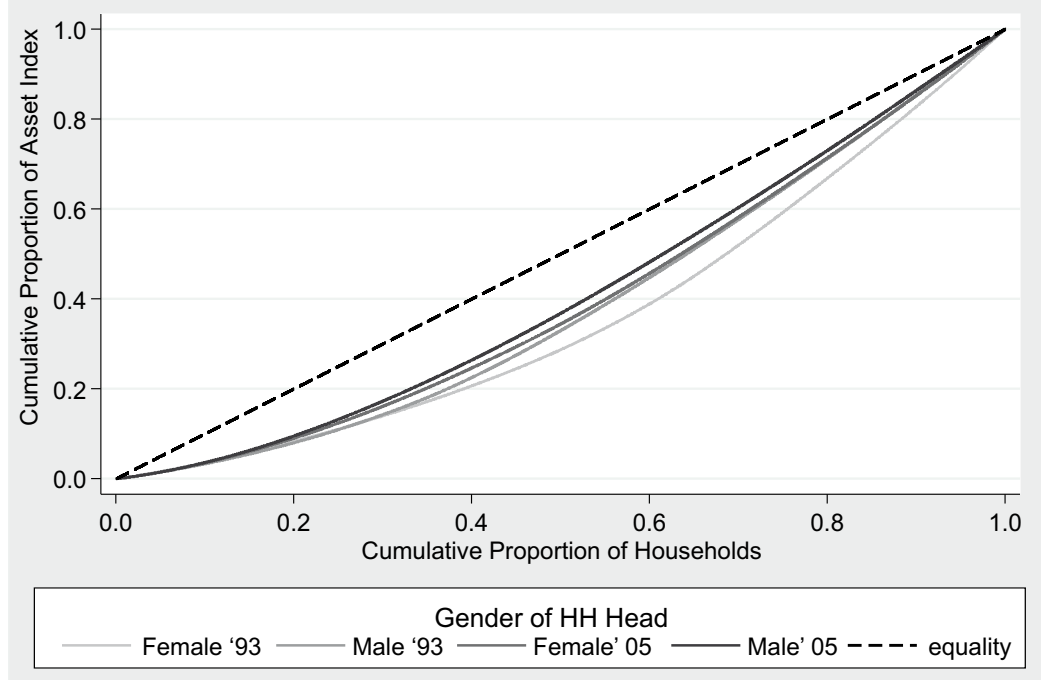

Source: PSLSD 1993 (SALDRU), GHS 2005 (Statistics South Africa); Own Calculations

The results from the Theil index according to the gender of the household head confirm that the difference in non-income inequality between male and female headed households is relatively small and that it has in fact decreased over the period. In 2005, more than 98 percent of total inequality was driven by the inequality within these two cohorts.

Table 11: Theil Index by Gender of Household Head for Non-income Inequality by Race for South Africa, 1993-2005

\begin{tabular}{|c|c|c|c|c|}
\hline By Gender of Household Head & 1993 & & 2005 & \\
\hline Within & 0.09443 & $96.2 \%$ & 0.0637 & $98.2 \%$ \\
\hline Between & 0.00378 & $3.8 \%$ & 0.00118 & $1.8 \%$ \\
\hline Over all & 0.09821 & & 0.06488 & \\
\hline
\end{tabular}

Source: PSLSD 1993 (SALDRU), GHS 2005 (Statistics South Africa); Own Calculations

Table 12 shows the Gini coefficients (calculated using our basic needs index) for the provinces in South Africa. These show that most provinces experienced a decline in non-income inequality between 1993 and 2005. (The increases in the Gini coefficients for Gauteng and the Northern Cape are not statistically significant.) 
Table 12: Gini Coefficient by Province for Non-income Inequality by Race for South Africa, 1993-2005

\begin{tabular}{lll} 
By Province & 1993 & 2005 \\
\hline Western Cape & 0.11 & 0.09 \\
Eastern Cape & 0.29 & 0.27 \\
Northern Cape & 0.11 & 0.13 \\
Free State & 0.28 & 0.15 \\
KwaZulu Natal & 0.29 & 0.23 \\
North West & 0.21 & 0.18 \\
Gauteng & 0.13 & 0.14 \\
Mpumalanga & 0.23 & 0.17 \\
Limpopo & 0.24 & 0.17 \\
Overall & 0.25 & 0.19 \\
\hline
\end{tabular}

Source: $\quad$ PSLSD 1993 (SALDRU), GHS 2005 (Statistics South Africa); Own Calculations

Notes: The changes in the values of the Gini coefficients between 1993 and 2005 are "in bold" when the results are statistically significant at the 95 percent level.

Six of the nine provinces, namely the Eastern Cape, Free State, KwaZulu-Natal, North West, Mpumalanga, and the Limpopo Province experienced statistically significant decreases in nonincome inequality over the period. (The decline in the Western Cape's Gini coefficient is not statistically significant.) These decreases range between two and thirteen percentage points, with the largest relative decline experienced by the Free State Province. Put differently, it appears as if the Free State benefited most from the increased service delivery by government over the period.

Table 13: Theil Index by Province for Non-income Inequality by Race for South Africa, 1993-2005

\begin{tabular}{lcccc} 
By Province & 1993 & & 2005 & \\
\hline Within & 0.07863 & $75.5 \%$ & 0.05684 & $87.6 \%$ \\
Between & 0.02553 & $24.5 \%$ & 0.00802 & $12.4 \%$ \\
Over all & 0.10417 & & 0.06486 & \\
\hline
\end{tabular}

Source: PSLSD 1993 (SALDRU), GHS 2005 (Statistics South Africa); Own Calculations

The Theil index by province shows that within-group inequality has been the key driver of total non-income inequality over the period. In fact, non-income inequality within provinces has become more important over time, with the contribution of this component increasing from 76 percent to almost 88 percent. Again, this suggests that while most provinces benefited from increased access to services and assets, significant backlogs still exit in all provinces. 
Overall, then, the evidence presented in this section has shown that, in contrast to the shifts in income inequality, non-income inequality - as measured using our basic services index - has decreased at the aggregate, for African households, in most provinces and for both male and female headed households. However, significant backlogs still exist. This highlights the opportunity for government to further impact on the levels of non-income inequality by targeting the delivery of basic services to those households that still do not have access to basic housing, water, electricity and sanitation. 


\section{The Relationship between Economic Growth, Poverty and Inequality: $1995-2005$}

There is very little debate, if any, amongst economists around the notion that a high level of economic growth is essential for poverty reduction. Indeed, increased growth rates, effectively measured by rising per capita incomes, would appear to make this link clear and simple: if you increase economic growth, poverty levels will fall in the society. However, a more detailed assessment of experiences around the world, indicate that there are two very important caveats to this generalised view that 'growth is good for the poor'. Firstly, the impact of economic growth on poverty differs significantly across countries. Hence, research from the World Bank, indicates that a two percent increase in growth rates will result in a reduction in poverty ranging from one to seven percent, depending on the country (Ravallion 2001). Secondly, as incomes grow, there is a high likelihood that this will also affect the distribution of that income. Put differently, economic growth often brings with it, some change in the levels of income inequality. When this occurs and if the result is an increase in inequality, the gains from growth to the poor may in fact be reduced. Higher inequality levels from growth 'stretch' the distribution of income and in so doing dilute the impact of economic growth on poverty. Given these two caveats to the growth-poverty nexus then, the critical insight is that economic growth may be necessary, but it is certainly not a sufficient condition for poverty reduction in a society.

Section 2.1 showed that nominal per capita income at the aggregate level, and in fact for all race groups, increased between 1995 and 2005. When the impact of inflation is taken into account, the results are mixed. African and Asians did not experience any change in their real per capita household income. At the aggregate level, however, real per capita household income did increase, while the White and Coloured population experienced significant increases in their real incomes over the period.

The evidence presented in Section 2.2 shows that over the same period, all South Africans experienced rising income inequality. The objective of this section is therefore to examine the relationship between economic growth, inequality and poverty between 1995 and 2005 and particularly the impact of the increasing income inequality on poverty levels.

We first examine how the growth in incomes of the poor has fared relative to those of the rich between 1995 and 2005. As a starting point for the analysis, we examine growth incidence curves (GIC) for this period according to a set of covariates. Methodologically, we draw on the work of Ravallion (2001) and Ravallion and Chen (2003), who developed these concepts. 
Essentially, the GIC approach allows us to determine whether growth in per capita household income in this period has been pro-poor in nature by plotting the growth in income across each centile of the distribution.

Pro-poor growth may be defined in two broad ways, one definition being stronger than the other. Growth may be considered pro-poor in an absolute sense if the change in income levels of the poor (as defined by a chosen poverty line) over a given time period is larger than zero, that is, the income levels of the poor have increased in absolute terms. Graphically, this definition is represented by a growth incidence curve that is located entirely above zero along the whole distribution. Alternatively, growth may be considered pro-poor in a relative sense if the change in the income levels of the poor is larger than the change in the income levels of the non-poor (Bhorat \& Van der Westhuizen 2007).

The GIC in Figure 10 shows that South Africa experienced absolute pro-poor growth between 1995 and 2005. It is, however, also clear that the growth in per capita income was not pro-poor in the relative sense. While the GIC may be above zero and thus meets the weaker criterion of pro-poor growth, it is upward sloping and confirms the results from the previous section which showed that inequality has increased significantly over the period, with the rich experiencing faster growth in their per capita incomes than the poor. 
Figure 10: Growth Incidence Curve for South Africa, 1995 - 2005

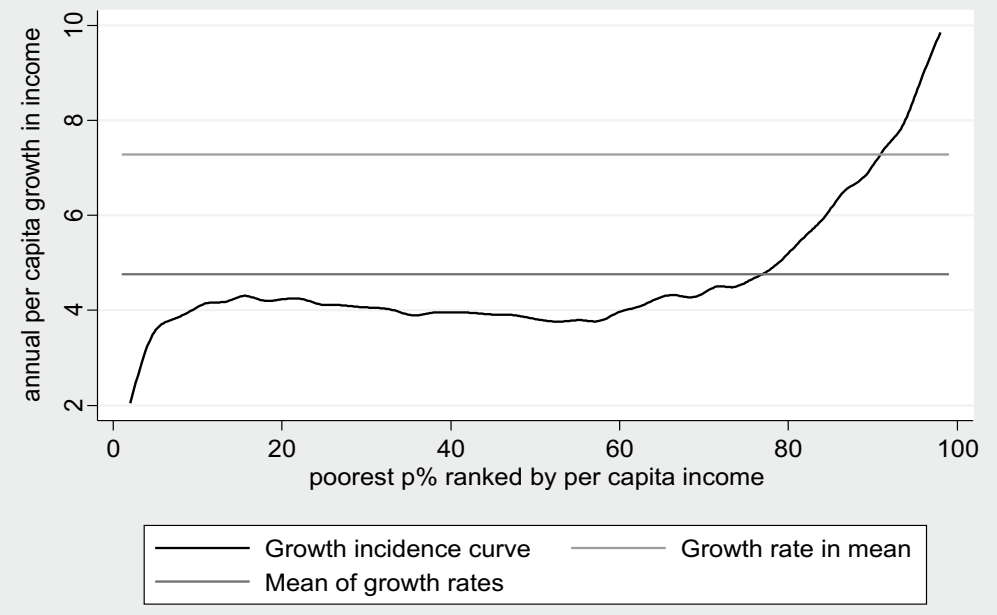

Source: Statistics South Africa (1995 and 2008) and Own Calculations

Notes: $\quad 1 . \quad$ The population in 1995 has been weighted according to the 1996 Census, while the population in 2005 has been weighted according to the 2001 Census. In both datasets, the population has been weighted by the household weight multiplied by the household size.

2. Figures are annualised growth rates

In fact, for most of the distribution, from approximately the 15th to the 75th percentile, we see a relatively low but stable growth rate of around four percent. Those at the very bottom of the distribution experienced the smallest increases in per capita income, with the average annual growth rate ranging between two and four percent. The growth rate increases quite sharply from the 80th percentile, and at the upper end of the distribution the average annual growth rate exceeds the mean of the growth rates of 4.8 percent. The average annual growth in mean per capita income was just above seven percent over the period.

Figure 11 presents the GIC for the African population between 1995 and 2005. Again, it is very clear that growth in per capita income was pro-poor in the absolute sense as all Africans experienced an increase in per capita income over the period. 
Figure 11: Growth Incidence Curve for Africans, 1995 - 2005

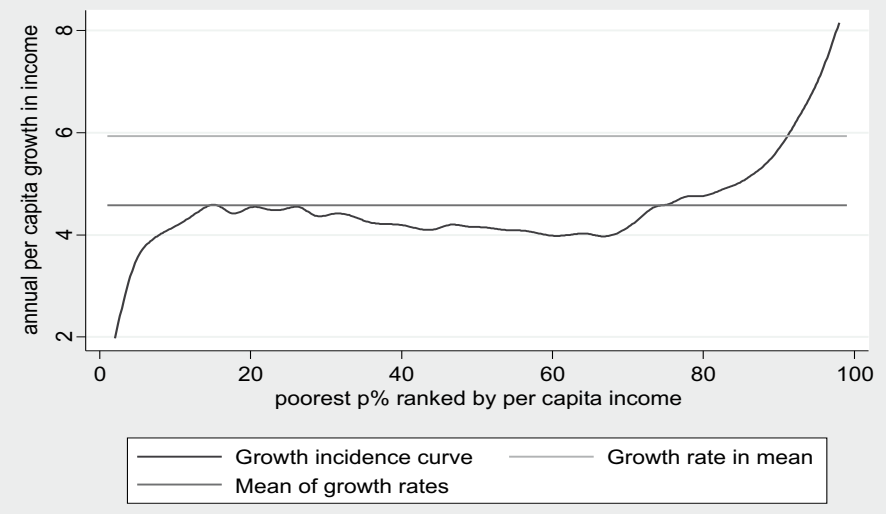

Source: Statistics South Africa (1995 and 2008) and Own Calculations

Notes: $\quad 1 . \quad$ The population in 1995 has been weighted according to the 1996 Census, while the population in 2005 has been weighted according to the 2001 Census. In both datasets, the population has been weighted by the household weight multiplied by the household size.

2.

Figures are annualised growth rates

The growth experience for the African population mirrors that of South Africa at the aggregate level, with growth not being pro-poor in the relative sense. Those below the 15th percentile, that is, the ultra-poor, experienced the lowest growth rates, while individuals between the 15th and 75th percentiles experienced growth rates below the mean of the growth rate of 4.6 per cent. Those at the top end of the income distribution, that is, from the 80th percentile upwards, experienced the highest growth rates. In fact, those at the very top of the distribution experienced average annual growth rates of more than eight percent - almost double the mean of the percentile growth rates.

The GIC's for the Coloured and White population (found in Appendix 10) confirm that, irrespective of race, all South Africans experienced absolute per capita income growth between 1995 and 2005. However, it is also clear that again, irrespective of race, those at the top end of the distribution experienced higher growth rates in their incomes than the poor and growth was not pro-poor in the relative sense.

The growth rates in the mean and median per capita income as well as the mean percentile growth rates at national level and for all four race groups are presented in Table 14. The rate of pro-poor growth for the poorest 10,15, 20, 25 and 30 percent of the distribution are also presented. 
Table 14: Measures of Pro-poor Growth, 1995-2005

\begin{tabular}{|c|c|c|c|c|c|}
\hline & Total & African & Coloured & Asian & White \\
\hline Growth rate in mean & 7.29 & 5.94 & 9.37 & 6.86 & 9.8 \\
\hline Growth rate at median & 3.78 & 4.14 & 6.09 & 5.29 & 8.19 \\
\hline Mean percentile growth rate & 4.76 & 4.58 & 7.06 & 4.84 & 8.41 \\
\hline \multicolumn{6}{|c|}{ Rate of pro-poor growth at corresponding percentile } \\
\hline 10 & 3.1 & 3.14 & 2.92 & -3.94 & 3.21 \\
\hline 15 & 3.47 & 3.56 & 3.58 & -2.54 & 3.99 \\
\hline 20 & 3.66 & 3.8 & 4.04 & -1.82 & 4.63 \\
\hline 25 & 3.77 & 3.94 & 4.37 & -1.26 & 5.13 \\
\hline 30 & 3.82 & 4.02 & 4.61 & -0.74 & 5.5 \\
\hline
\end{tabular}

Source: $\quad$ Statistics South Africa (1995 and 2008) and Own Calculations

Notes: $1 . \quad$ The population in 1995 has been weighted according to the 1996 Census, while the population in 2005 has been weighted according to the 2001 Census. In both datasets, the population has been weighted by the household weight multiplied by the household size.

2. Figures are annualised growth rates

The evidence presented in Table 14 confirm that at the national level, and for the African, Coloured and White population, the rate of pro-poor growth increases as one moves from the 10th to the 30th percentile. However, none of the individuals in the bottom 30 percent of the distribution experienced growth in per capita income higher than the mean growth rate. The White population generally experienced higher growth rates in per capita income than other race groups, with the African population exhibiting the lowest growth rates when compared to their White and Coloured counterparts.

Asians at the bottom of the income distribution experienced negative growth rates over the period. The very small sample size, however, makes it difficult to interpret these results in a meaningful manner.

Figure 12 and Figure 13 present the GICs for urban and rural areas. These show that although absolute pro-poor growth occurred in both rural and urban areas, there was no relative pro-poor growth since those at the top of the distribution experienced higher growth rates than those at the bottom of the distribution. 
Figure 12 Growth Incidence Curve for Urban Households, 1995 - 2005

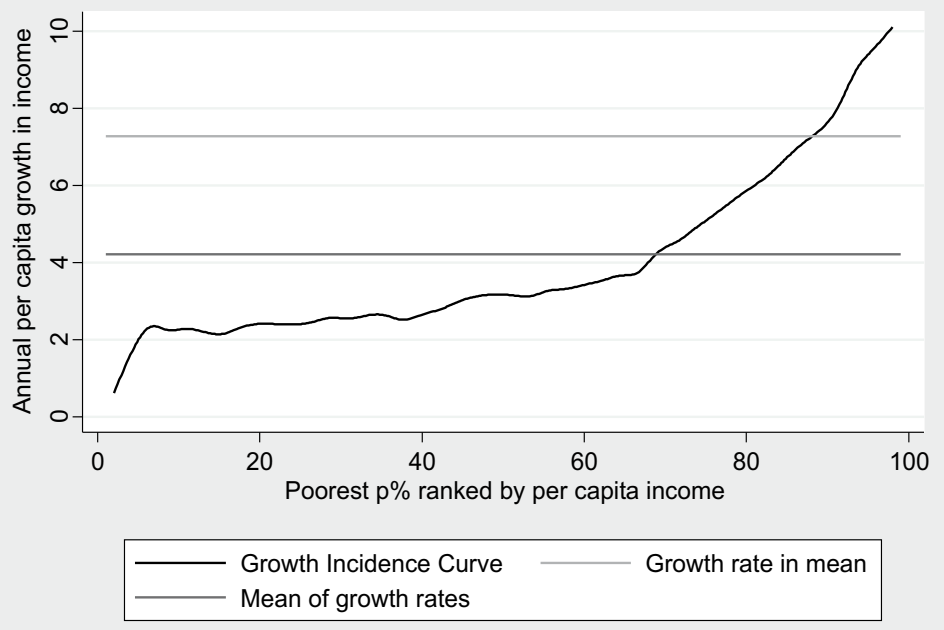

Source: $\quad$ Statistics South Africa (1995 and 2008) and Own Calculations

Notes: $\quad 1$. The population in 1995 has been weighted according to the 1996 Census, while the population in 2005 has been weighted according to the 2001 Census. In both datasets, the population has been weighted by the household weight multiplied by the household size.

2. Figures are annualised growth rates

The GIC for urban areas is upward sloping which confirms the inequality results in the previous section, that is, that income inequality in urban areas has increased as a result of relatively higher growth experienced by those at the top of the distribution. In addition, we find that the growth rates in urban areas only surpassed the mean of growth rates (of four percent) after the 70th percentile. While the growth rate is relatively stable from approximately the fifth to the 65th percentile, it increases quite rapidly from the 70th percentile onwards. At the very top of the distribution, the average annual growth rate of ten percent is more than double the mean of the percentile growth rates.

Rural and urban areas followed different growth paths over the period. At the upper ends of the distribution, the growth rates are significantly higher in the urban areas. In the previous section, we saw that wage inequality is the main driver of total income inequality. Specifically, we saw that the wage premium paid to highly skilled workers is one of the main contributing factors to wage inequality. The result presented here may reflect the fact that highly skilled and highly paid workers generally reside in urban areas. 
Figure 13 Growth Incidence Curve for Rural Households, 1995 - 2005

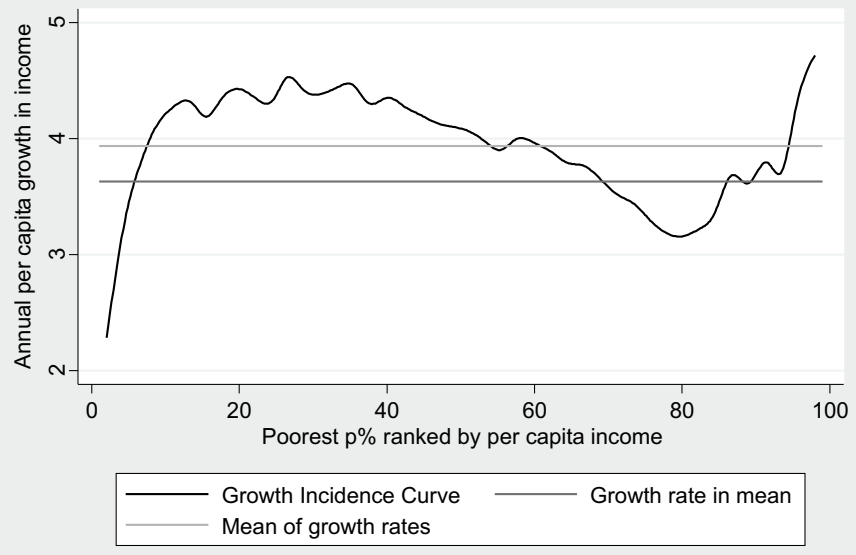

Source: Statistics South Africa (1995 and 2008) and Own Calculations

Notes: 1 . The population in 1995 has been weighted according to the 1996 Census, while the population in 2005 has been weighted according to the 2001 Census. In both datasets, the population has been weighted by the household weight multiplied by the household size.

2. Figures are annualised growth rates

Another important difference between the two GICs is the range of the growth rates. For individuals living in urban areas, the average annual growth rates in per capita incomes range between less than zero to more than ten percent, while the growth rates for rural areas vary between just more than two and less than five percent. This relatively narrow range of growth rates also explains why income inequality for individuals living in rural areas did not change significantly over the period.

Rural residents in the bottom half of the income distribution generally benefited more from economic growth than those in the top 50 percent, with the exception of those at the very top and the very bottom. This trend may be a reflection of how the provision of social grants benefited the poor in rural areas, with only those at the very top of the distribution benefiting from higher wages.

Figure 14 presents the GICs for male- and female-headed households respectively. Again, it is clear that growth was pro-poor in the absolute sense for all individuals between 1995 and 2005 , irrespective of the gender of the head of the household that they resided in. 
Figure 14: Growth Incidence Curve for Male-Headed Households, 1995 - 2005

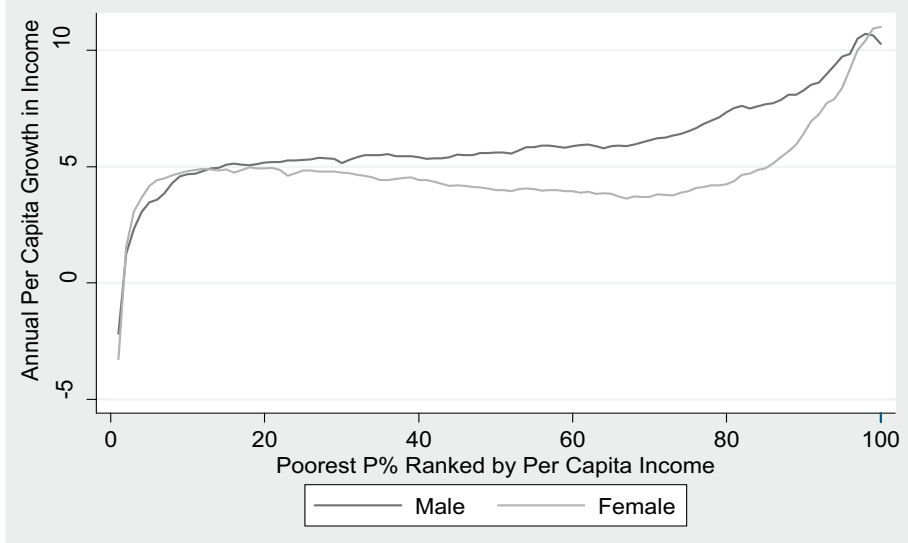

Source: Statistics South Africa (1995 and 2008) and Own Calculations

Notes: 1 . The population in 1995 has been weighted according to the 1996 Census, while the population in 2005 has been weighted according to the 2001 Census. In both datasets, the population has been weighted by the household weight multiplied by the household size.

2. Figures are annualised growth rates

Both GICs display a trend similar to that of the GIC for South Africa, with individuals at the bottom of the distribution experiencing lower average annual growth rates than those at the upper end of the distribution. In addition, the average annual growth rate for the majority of individuals falls below the mean of the growth rates (6.0 percent for individuals living in maleheaded households and 4.8 percent for those living in female-headed households - not shown on the graph).

We also find that at the bottom of the distribution, individuals living in female-headed households fared slightly better than individuals living in male-headed households. However, individuals in the middle of the distribution living in a household headed by a male experienced higher growth rates in per capita income than those in female-headed households. This result may reflect the fact that women remain over-represented in low-skilled, low-paying jobs and that, especially in the low and semi-skilled occupations, women continue to earn less than their male counterparts. Living in male-headed as opposed to female-headed households did not impact differently on the growth in per capita income for individuals at the top end of the distribution. This may reflect that, in contrast to unskilled and semi-skilled occupations, women occupying highly skilled positions have been experiencing a decline in the gender wage gap. 
The pro-poor growth measures for individuals living in male-headed and female-headed households are presented in Appendix 11. These show that while male-headed households experienced higher mean average annual growth rates than female-headed households, female-headed households enjoyed higher average annual growth rates at the 10th, 15th, 20th and 25th percentiles than both at the aggregate level and for male-headed households.

To summarise then, while all individuals experienced absolute pro-poor growth in South Africa between 1995 and 2005, those at the top end of the distribution experienced higher growth rates than those at the bottom. This result holds true across race, location and gender of the household head and confirms a growth trajectory marked by a decrease in poverty levels, but sharply rising income inequality.

\section{The Impact of Growth and Inequality on Poverty}

While the GICs and the pro-poor growth rates do take us some way beyond the static comparison of poverty shifts over a time period, one of the important value-added questions is to try and gauge the influence of both economic growth and changing inequality levels on reported poverty changes. We attempt below different approaches in trying to empirically detail this relationship, concentrating firstly on the growth-poverty elasticity and the influence of inequality shifts on this measure, and secondly on the Datt-Ravallion decomposition.

It is possible, by drawing on the work of Kakwani et al (1993), to compute the impact of economic growth on poverty levels. In addition though, it is argued that the process of economic growth may induce shifts in inequality which, in of themselves, may erode some or all of the growth-associated poverty reduction gains. In attempting to deal more broadly with the different interactions between poverty, inequality and growth, we follow the methodology proposed by Kakwani et al (1993), which essentially provides for three useful measures reflecting on the link between poverty, inequality and growth. The first of these is a distributionneutral measure of the poverty-growth elasticity. The measure is readily estimated using the following equation when utilising the $P_{\alpha}$ class of poverty measures:

$$
\eta_{P_{\alpha}}=-\alpha\left[\frac{P_{\alpha-1}-P_{\alpha}}{P_{\alpha}}\right] \text { for } \alpha \neq 0
$$


Essentially, this equation measures the 'pure growth' effect on poverty reduction, independent of the distribution of income. However, in a period of economic growth, the income distribution changes can and often do occur. Hence, as noted above, it is entirely possible that despite economic growth, subsequent changes in the distribution of income may militate against any significant reduction in poverty. We can measure this relationship between poverty and inequality (as measured by the Gini), when utilising the $P_{\alpha}$ class of poverty measures (Kakwani et al 1993) as:

$$
\varepsilon_{P_{\alpha}}=\eta_{P_{\alpha}}+\frac{\alpha \mu P_{\alpha-1}}{z P_{\alpha}} \text { for } \alpha \neq 0
$$

Given the simultaneous impact of mean income growth and inequality on poverty, an important issue then is what increase in mean income is required to mitigate against distributional outcomes eroding poverty reduction gains. We can measure this for the FGT class of poverty measures, again according to Kakwani et al (1993) as:

$$
M P R S=-\frac{\varepsilon_{P_{\alpha}}}{\eta_{P_{\alpha}}}
$$

where the MPRS refers to the marginal proportional rate of substitution between mean income and income inequality.

Table 15 estimates the above relationships for 1995 and 2005, utilising both the R322 poverty line, and the R174 line. We first examine the poverty-mean income elasticities. In 1995, using the R322 a month poverty line, a one percent increase in (individual) mean per capita household income would reduce the poverty gap by just 1.22 percent. By 2005, this elasticity has declined slightly to just above one percent, meaning that a one percent increase in mean per capita income would lead to a slightly smaller reduction in the poverty gap. In other words, growth (as measured by the increase in mean per capita income) became slightly less pro-poor over the decade. The same trend is observed at the R174 poverty line, with the additional result that growth in income has a relatively larger impact on the poor at that level. At both poverty lines, the impact of increased income on the squared poverty gap also became marginally smaller over the period.

These elasticity estimates, however, assume a constant Lorenz Curve, and hence do not take account of the distributional effects of the growth process. The crucial caveat to the above 
growth-poverty nexus therefore, lies in the distributional changes that may occur in the growth process. Hence, if inequality increases during a growth phase, then there is a possibility that poverty levels may in fact increase even if per capita income did increase over the same period - a fact that we will turn to in greater detail below. The second set of measures, namely the poverty-inequality elasticity estimates, provides an indication of this sensitivity.

Table 15 Elasticities of Poverty Measures for South Africa. 1995 and 2005

\begin{tabular}{lcccc} 
Category & \multicolumn{2}{c}{ R322 poverty line } & \multicolumn{2}{c}{ R174 poverty line } \\
\hline Year & 1995 & 2005 & 1995 & 2005 \\
& & & & -1.62 \\
P1-growth elasticity & -1.22 & -1.06 & -1.91 & -1.78 \\
P2-growth elasticity & -1.50 & -1.30 & -2.24 & 15.63 \\
Gini-P1 elasticity & 5.87 & 6.29 & 15.32 & 23.14 \\
Gini-P2 elasticity & 9.69 & 10.47 & 22.85 & 9.68 \\
MPRS P1 & 4.82 & 5.91 & 8.00 & 13.01 \\
MPRS P2 & 6.45 & 8.04 & 10.19 & \\
\hline
\end{tabular}

Source:

Statistics South Africa (1995 \& 2005) and Own Calculations

Notes: 1 . The population in 1995 has been weighted according to the 1996 Census, while the population in 2005 has been weighted according to the 2001 Census. In both datasets, the population has been weighted by the household weight multiplied by the household size.

2. The 'Poor' category refers to poverty measures based on a poverty line of R322 per capita per month in 2000 prices, while the 'Ultra-Poor' category is based on a poverty line of R174 per capita per month.

The poverty gap-Gini elasticity indicates that in 1995, on the R322 poverty line, a one percent increase in the Gini coefficient would increase the poverty gap by 5.9 percent, while it would increase the squared poverty gap by almost ten percent. These elasticities increased marginally in 2005, suggesting that the impact of inequality on poverty has increased over the decade. In both years, the elasticities are even larger when the R174 poverty line is considered. By 2005, a one percent increase in the Gini coefficient would increase the squared poverty gap by just over 23 percent.

The final measure, the MPRS, provides some sort of policy benchmark in that it indicates the levels of economic growth that may maximise poverty reduction gains in the environment of growing inequality. In other words, it tells us the growth in mean per capita income that is needed to compensate for a one percent increase in inequality as measured by the Gini coefficient.

In 1995, the MPRS with respect to the poverty gap indicated that per capita income would have to increase by 4.8 percent to compensate for a one percent in increase in the Gini 
coefficient. By 2005, this measure increased to almost six percent. The figures indicate that the MPRS increased between 1995 and 2005 for both the poverty gap and the squared poverty gap. In all cases the MPRS is higher for the squared poverty gap than for the poverty gap, implying that the measure increases when the poverty aversion parameter $\alpha$, increases. In addition, the MPRS is higher for the lower poverty line, suggesting that a greater economic growth response is required when trying to compensate for the distributional outcomes experienced by the ultra poor.

Our next set of estimates, the Datt-Ravallion decompositions (Datt \& Ravallion 1992), complement the Kakwani estimates very well and deepens our understanding of the relative contributions of economic growth and distributional shifts to measured poverty outcomes.

Very briefly, the Datt-Ravallion methodology revolves around decomposing the change in measured poverty into a growth and redistribution component. The growth component refers to the change in poverty that occurs, if we assume that inequality does not change. The redistribution component is the change in poverty, if mean income levels had not altered (that is, no growth has taken place). Finally, a residual variable captures the interaction between the growth and redistribution effects on poverty. If we take the equation $P(z / u, \Pi)$, where $z$ is the poverty line, $u$ the mean income level and $\Pi$ the Lorenz Curve, then the decomposition proceeds as follows:

$$
P_{t+1}-P_{t}=G(t, t+1 ; r)+D(t, t+1 ; r)+R(t, t+1 ; r)
$$

Where $t$ and $t+1$ are the two time periods under discussion, $P$ the poverty measure in the two time periods, $G($.) represents the growth component, $D($.) the redistribution and $R($.) the residual components of the decomposition. We can define the growth and redistribution components in turn by the following:

$$
\begin{aligned}
& G(t, t+1 ; r) \equiv P(z / u t+1, \Pi r)-P(z / u t, \Pi r) \\
& D(t, t+1 ; r) \equiv P(z / u r, \Pi t+1)-P(z / u r, \Pi t)
\end{aligned}
$$

Where $r$ makes explicit the reference date with respect to the decomposition of the poverty shift (Datt \& Ravallion 1992). In essence then, the above measure enables one to examine and discretely measure the relative contributions of changing inequality versus changing income growth to overall poverty changes. 
Table 16 presents the results of the Datt-Ravallion decompositions for South Africa between 1995 and 2005 at the aggregate level, by race, by gender of household head and according to two standard poverty lines (R322 and R174 a month in 2000 prices). The growth component refers to the growth in per capita income and the total change in poverty refers to the change in the headcount rate as measured by per capita income.

The result from the Datt-Ravallion decompositions show that poverty levels (as measured by per capita income) increased at the aggregate level as well as for all race groups, and irrespective of the gender of the head of the household. The key result here is that the increasing levels of income poverty for all South Africans have been the result of the changing distribution of income (that is, increasing inequality) eroding any poverty gains realised from the growth in nominal per capita income over the period.

Table 16: Datt-Ravallion Decompositions by Race and Gender of Household Head, 1995-2005

\begin{tabular}{lccc} 
Category & Growth component & Redistribution component & Total change in poverty \\
\hline Poverty Line R322 per month & & & \\
Total & -21.24 & 28.65 & 7.42 \\
African & -19.90 & 27.41 & 7.51 \\
Coloured & -30.03 & 31.40 & 1.36 \\
Asian & -9.70 & 21.24 & 11.54 \\
White & -2.80 & 4.16 & 1.36 \\
Male-Headed & -23.41 & 25.49 & 2.08 \\
Female-Headed & -23.17 & 31.37 & 8.20 \\
Poverty Line R174 per month & & & \\
Total & -20.62 & 26.87 & 6.26 \\
African & -20.65 & 27.23 & 6.58 \\
Coloured & -18.55 & 21.58 & 3.04 \\
Asian & -5.35 & 11.01 & 5.66 \\
White & -0.78 & 1.91 & 1.12 \\
Male-Headed & 19.40 & 21.89 & 2.50 \\
Female-Headed & -26.85 & 33.64 & 6.79 \\
\hline
\end{tabular}

Source: $\quad$ Statistics South Africa (1995 \& 2005) and Own Calculations

Notes: 1 . The population in 1995 has been weighted according to the 1996 Census, while the population in 2005 has been weighted according to the 2001 Census. In both datasets, the population has been weighted by the household weight multiplied by the household size.

2. The poverty shifts are based on the headcount measures and the two poverty lines of R322 and R174 respectively.

3. Residual values were zero in all cases 
For example, at the aggregate and when using the R322 poverty line, the increase in per capita income (as illustrated by the growth component) accounted for a decline of more than 21 percentage points in the income poverty headcount rate between 1995 and 2005 . Over the same period, the redistribution component accounted for an increase of almost 29 percentage points in the headcount rate. The overall result was an increase of more than seven percentage points in the national headcount rate. In other words, the relatively larger contribution of the redistribution component has meant that poverty increased over the period despite increasing levels of per capita income.

The results of the decompositions also show that the redistribution component outweighed the growth component at both the R322 and R174 poverty lines and for all individuals, irrespective of race or the gender of the household head.

The results of the Datt-Ravallion decompositions by province are shown in Appendix 9. With the exception of the Free State at both lines and the Eastern Cape at the R174 line, all provinces experienced an increase in their levels of income poverty as a result of the contribution of the redistribution component outweighing the contribution of the growth component. Put differently, in most provinces, individuals experienced an increase in their income poverty as a result of the increasing levels of inequality eroding the poverty gains associated with higher per capita incomes. For example, Kwazulu-Natal experienced an increase in its headcount rate of more than 17 percentage points at the R322 line. While the growth component contributed to a decline of almost 15 percentage points in the headcount rate, we saw earlier that the province Gini coefficient increased from 0.61 to 0.71 over the same period. This rising inequality contributed a massive 32.5 percentage points to the province's headcount rate, completely eroding the contribution of the growth component.

The evidence presented above confirms that growth has been inherently unequal in the period between 1995 and 2005, caused by the changing distribution of income. The process of growth and its nature has undermined the gains from economic growth in terms of poverty reduction. The nature of the growth trajectory is based upon, amongst other things: the exclusion of the second economy and the dominance of the first economy; the high concentration levels of the first economy and the high barriers to entry and the capital intensive nature of the production system in combination with the demand for highly skilled workers. Those involved in the second economy are unable to benefit from the opportunities presented by economic growth and are therefore trapped at the bottom of the end of the distribution. Furthermore, economic activity is concentrated in the formal market, which has high barriers 
to entry preventing the bottom of the distribution from partaking in it. Barriers to entry include restricted access to the credit market - the poor do not have collateral to secure loans so that they are able to participate in the formal market. The poor are generally poorly uneducated and have low skills - characteristics preventing the mass of the population from entering the formal economy and benefitting from economic growth. 


\section{Policy Interventions to Mitigate the Impact of Rising Inequality in South Africa}

The evidence presented in previous sections has shown that wage inequality is undoubtedly the leading cause of income inequality. Not only is wage income the greatest source of income, but the distribution of it is highly skewed, with labour market participants being rewarded for the type (or level) of skill owned. While little can be done in the short-term to dampen the effect of wage inequality on income inequality, government can redistribute income via other means such as the provision of social grant income to poor households.

\subsection{The Impact of the Increased Provision of Social Grants}

One of the policies that government has implemented quite successfully is the provision of social grants. These grants are generally well targeted and mostly reach the poorest of the poor. Grants are targeted at the most vulnerable members of society, specifically the disabled, the aged and children. Grant income has been found to make a substantial contribution to total income, and is often used to support an entire household.

Pauw and Mncube (2007) provide a detailed analysis of the increase in government spending on social assistance and show that not only has the share of social grant expenditure in GDP increased significantly, but the number of social grant recipients has also increased significantly between 1996 to 2006. Government transfers grew from 2.5 percent of GDP in $1996 / 97$ to just over three percent in $2005 / 06$. The total number of grant beneficiaries increased from approximately three million in 1997 to 9.4 million in 2005 . This translates into an average annual growth rate of 15.3 percent.

The provision of grants accelerated after 2000. Grant expenditure increased from R20 553 million in 2001/02 to R51 927 million in 2005/06, which represents a 26.1 percent growth in social assistance expenditure by the government. The number of grant beneficiaries increased significantly over this relatively short period, from 3.61 million to 9.40 million. While all grants experienced a significant increase in the number of beneficiaries between 2001 and 2005, the number of Child Support Grant recipients increased from 975000 in 2001 to 5.6 million in 2005. This surge was due to both the increased public awareness of the grants and the extension of the grant to children up to the age of 14 years (Pauw \& Mncube 2007). A key aspect of the post-apartheid fiscal expenditure patterns has therefore been a widening and deepening of South Africa's social security system. 
Figure 15 illustrates the changes in access rates to the state grants by income deciles between 1995 and 2005 in South Africa. The access rate is the percentage of households in each income decile which received grant income in these two years.

Figure 15 Access rates of State Transfers South Africa, 1995 - 2005

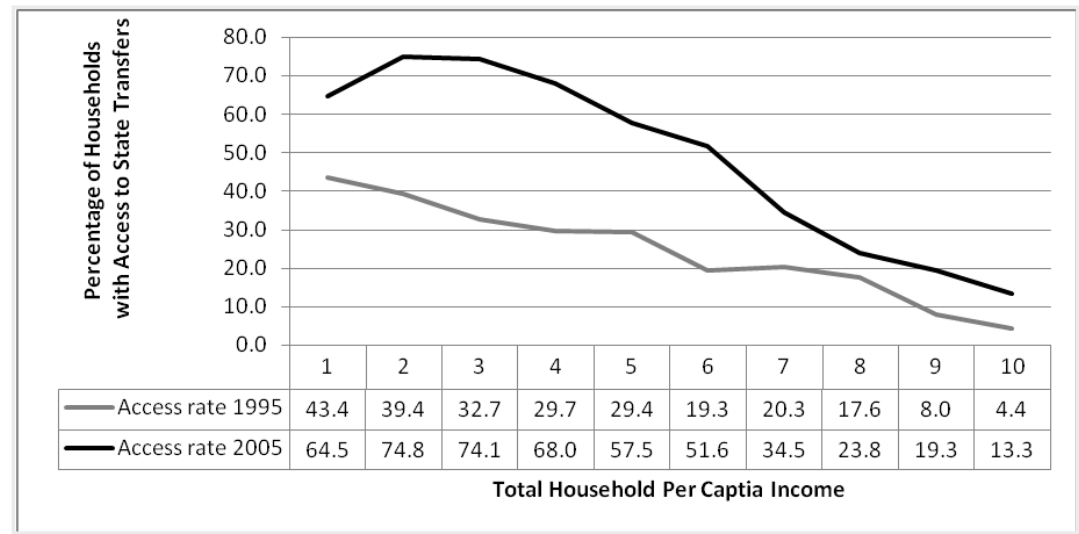

Source: $\quad$ Statistics South Africa (1995 and 2008) and Own Calculations

Notes: 1 . The population in 1995 has been weighted according to the 1996 Census, while the population in 2005 has been weighted according to the 2001 Census. In both datasets, the population has been weighted by the household weight multiplied by the household size.

There has been a significant increase in the access rates across the deciles between 1995 and 2005. For example, the share of households in the first decile with access to grant income increased from 43.4 percent in 1995 to 64.5 percent in 2005 . However, access to grant income not only increased significantly at the bottom deciles, but also in the deciles in the middle of the income distribution. For example, in the 6th decile the share of households with access to grant income increased from 19 percent to more than 50 percent. This is an important result, as it shows that grant income not only supports the very poor, but also a large portion of households in the middle of the distribution. In fact, between 50 and 75 percent of households in the bottom six deciles of the distribution received grant income in 2005.

Figure 16 shows per capita grant income as a proportion of total per capita household income for South Africa between 1995 and 2005. This confirms that not only has grant income been an important source of income for the poor, but that the share of grant income in total household income has increased significantly over the period. 
Figure 16: Per capita grant income as proportion of total household income, South Africa, 1995 and 2005

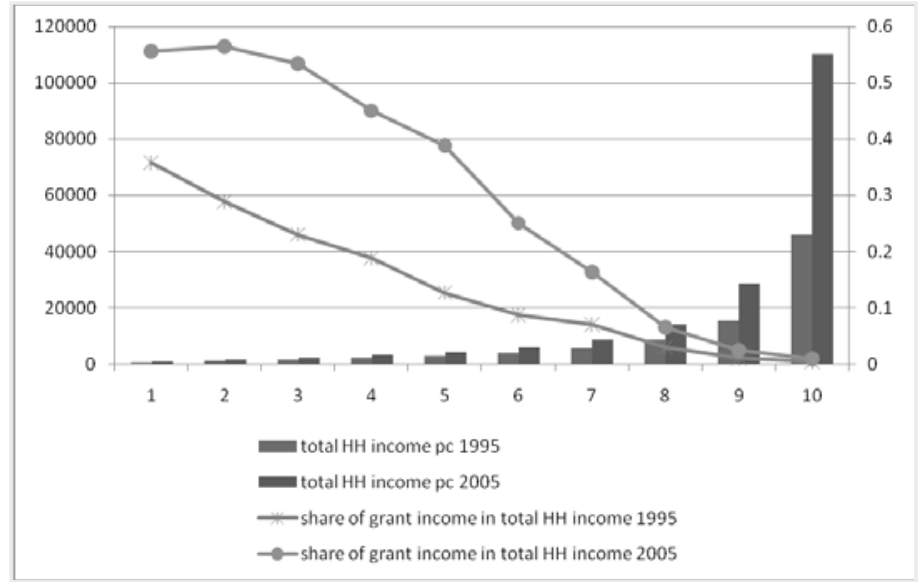

Source: $\quad$ Statistics South Africa (1995 and 2008) and Own Calculations

Notes: $1 . \quad$ The population in 1995 has been weighted according to the 1996 Census, while the population in 2005 has been weighted according to the 2001 Census. In both datasets, the population has been weighted by the household weight multiplied by the household size.

In 1995 the share of grant income in total per capital income was relatively low. This reflects the relatively limited number of South Africans who were grant recipients during that time. Even in the bottom decile, grant income only contributed about 35 percent to total income in 1995. The number of grant beneficiaries and therefore the contribution of grant income to total income increased significantly between 1995 and 2005. Furthermore, we observe that grant income has become an important contributing source to total income in all the lower income deciles. Even at the fifth income decile, we observe that grant income accounted for almost 40 percent of total income in 2005. As discussed earlier, we see that even in the eighth decile, grant income accounted for almost ten percent of total income, a result driven by the fact that even individuals in this income decile had such low levels of income in the absence of grants that they qualified to receive a social grant (see Appendix 1 for the mean income across deciles).

\section{Social Grants as a Suppressor of Income Inequality}

It is very clear from Figure 16 that grant income is an important source of income, even for those in the middle of the income distribution. The Gini decomposition in the earlier section was not able to adequately capture the significance of grant income for decreasing income inequality specifically due to the fact that grant income contributes significantly to total income up to the sixth decile. We have however observed that grant income had contributed significantly to total per capita income in particularly in 2005 , and therefore deemed it 
necessary to investigate what the levels of income inequality would have been in the absence of the provision of grants.

In order to estimate what the levels of inequality in South Africa would have been in the absence of the provision of social grants by government, we estimate the Gini coefficient, the Lorenz Curve and the Growth Incidence Curve for South Africa and by population group, using total per capita household income excluding grant income.

Table 17 shows that grant income played a crucial role in mitigating the impact of income inequality over the period.

Table 17: Gini Coefficients for Total Per Capita Income with and without Grant Income by Race, 1995 and 2005

\begin{tabular}{|c|c|c|c|c|c|c|}
\hline \multicolumn{7}{|c|}{ Gini Coefficient } \\
\hline & \multicolumn{2}{|c|}{1995} & \multirow[b]{2}{*}{$\begin{array}{l}\text { Change in } \\
\text { Gini Units }\end{array}$} & \multicolumn{3}{|c|}{2005} \\
\hline & $\begin{array}{c}\text { Per capita } \\
\text { income }\end{array}$ & $\begin{array}{c}\text { Per capita } \\
\text { income } \\
\text { without } \\
\text { grants }\end{array}$ & & $\begin{array}{c}\text { Per capita } \\
\text { income }\end{array}$ & $\begin{array}{c}\text { Per capita } \\
\text { income } \\
\text { without } \\
\text { grants }\end{array}$ & $\begin{array}{l}\text { Change in } \\
\text { Gini Units }\end{array}$ \\
\hline African & 0.56 & 0.59 & 0.03 & 0.61 & 0.71 & 0.10 \\
\hline Coloured & 0.49 & 0.52 & 0.03 & 0.59 & 0.64 & 0.04 \\
\hline Asian & 0.46 & 0.47 & 0.01 & 0.56 & 0.57 & 0.01 \\
\hline White & 0.44 & 0.44 & 0.00 & 0.51 & 0.52 & 0.01 \\
\hline Overall & 0.64 & 0.66 & 0.02 & 0.72 & 0.77 & 0.05 \\
\hline
\end{tabular}

Source: $\quad$ Statistics South Africa (1995 and 2008) and Own Calculations

Notes: 1. The changes in the values of the Gini coefficients between 1995 and 2005 are "in bold" when the results are statistically significant at the 95 percent level.

2. The population in 1995 has been weighted according to the 1996 Census, while the population in 2005 has been weighted according to the 2001 Census. In both datasets, the population has been weighted by the household weight multiplied by the household size.

The results are striking: the Gini coefficient increases significantly (irrespective of the year or race group) when grant income is excluded. The social security system in South Africa has thus contributed significantly to lowering the overall levels of inequality in the country.

At the aggregate the Gini coefficient increases from 0.72 to 0.77 in 2005 when grant income is excluded from total income, showing that grant income reduced income inequality considerably in 2005 . The evidence also suggests that grant income played a greater role in the mitigation of income inequality in 2005 than in 1995. This result is not surprising, given the 
large increase in both the number of beneficiaries and the expenditure on social grants over the period.

The results from Table 17, however, contrast with earlier findings (see Table 7), which did not capture the role of state grants as far as its contribution to income inequality is concerned. The results from the Gini decomposition did not reflect this critical contribution of social grants to the reduction of income inequality. The difference in the results can to a large extent be explained by the differences in the methodology used when calculating the various measures. As far as the decomposition is concerned, we find that grant income is distribution neutral, that is, grant income has no effect on income inequality, since a large number of grant beneficiaries can be found in the middle of the distribution. This was clearly illustrated by Figure 15, which showed that even in the Sixth income decile, a large share of individuals received grant income in 2005. In the absence of grant income, the individuals would have had levels of per capita household income, which would have located them in the lowest income deciles. The provision of grant income increased the mean income of these individuals and therefore moved them into higher income deciles.

The Gini decomposition method does not recognise this improvement in mean per capita income, but by estimating the Gini coefficient first including and then excluding grant income from total per capita income, we are able to capture the significance of grant income. Grant income has a stabilising effect on total income, and reduced income inequality significantly in both years. This result holds true for aggregate income inequality and for income inequality for the African population. For example, in 2005 , income inequality amongst the African population would have been 0.71 in the absence of the provision of social grants. When grant income is included, the Gini coefficient declines significantly to 0.61 .

The Lorenz Curve in Figure 17 confirms the results of the Gini coefficient, and graphically illustrates the relatively higher levels of income inequality in the absence of the provision of social grants. 
Figure 17: Lorenz Curves for Africans: With and Without Grant Income, 1995 and 2005

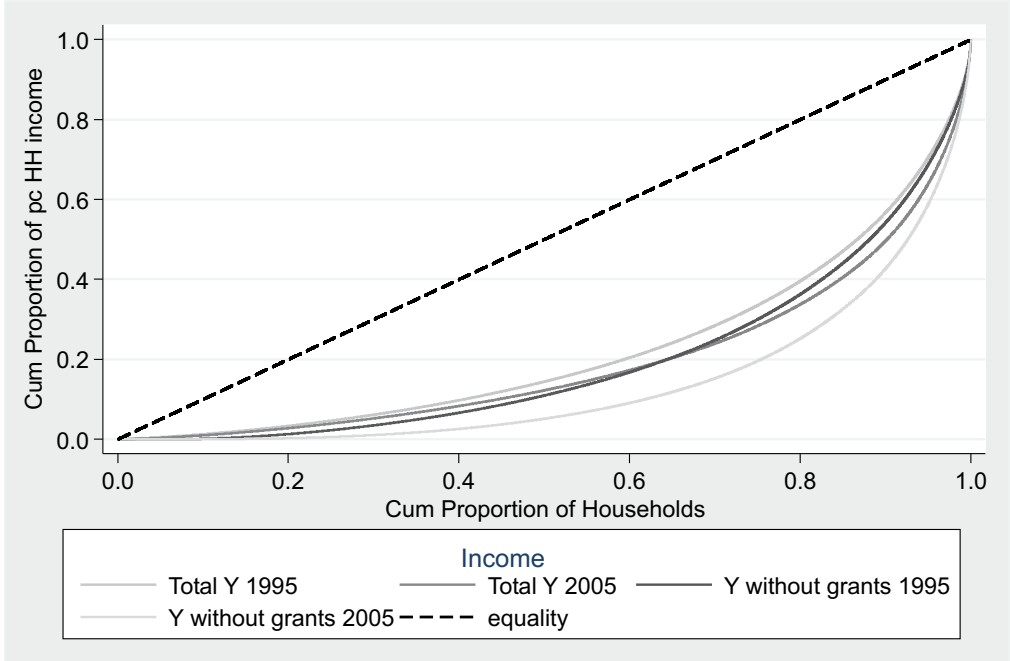

Source: $\quad$ Statistics South Africa (1995 and 2008) and own calculations

Notes: 1. The changes in the values of the Gini coefficients between 1995 and 2005 are statistically significant at the 95 percent level.

2. The population in 1995 has been weighted according to the 1996 Census, while the population in 2005 has been weighted according to the 2001 Census. In both datasets, the population has been weighted by the household weight multiplied by the household size.

The Lorenz Curves for both years show the impact of the provision of social grants, with both curves for income without grants lying further away from the "equality line" than the curves for income including grants. In addition, the relatively larger gap between the two curves for 2005 captures the relatively larger impact the provision of social grants had in 2005 . For example, the curves illustrate that in $\mathbf{2 0 0 5}$ when grant income is excluded from total income, the "bottom" 80 percent of individuals would have received only about 20 percent of total income. When grant income is included, the "bottom" 80 percent of individuals received more than 30 percent of total income.

The results for the Gini coefficient with and without grant income as a source of income for the nine provinces and by gender of household head are presented in Appendix 12. The results show that grant income made a significant difference to income inequality regardless of location and the gender of household head. Grant income played an especially important role in the mitigation of income inequality in the Eastern Cape, where the Gini coefficient increases from 0.69 to 0.80 in 2005 when grant income is excluded from total income. The provision of grants also had a relatively larger impact on inequality for individuals living in households headed by females. Specifically, the Gini coefficient declines from 0.80 to 0.68 when grant income is included as a source of income for individuals living in a household headed by 
a female, while the Gini coefficient for individuals living in male-headed households only decreases from 0.73 to 0.70 when grant income is excluded.

In the next section we compare two GICs, with grant income included and excluded respectively. We are therefore able to observe the impact of the provision of social grants on the growth rates at different percentiles of the income distribution. The results are quite startling, as the average annual growth rates for those at the bottom of the income distributing becomes negative in the absence of social grants. In fact, the percentile growth rates are negative up to about the 40th percentile of the distribution. In other words, in the absence of the provision of grant income growth would not have been pro-poor even in the absolute sense over the period.

The mean percentile growth rate is also significantly lower at 1.7 per cent when grant income is excluded, compared to 4.8 per cent when grants are included as a source of income.

Figure 18: Growth Incidence Curve Total per capita income excluding Grants South Africa, 1995-2005

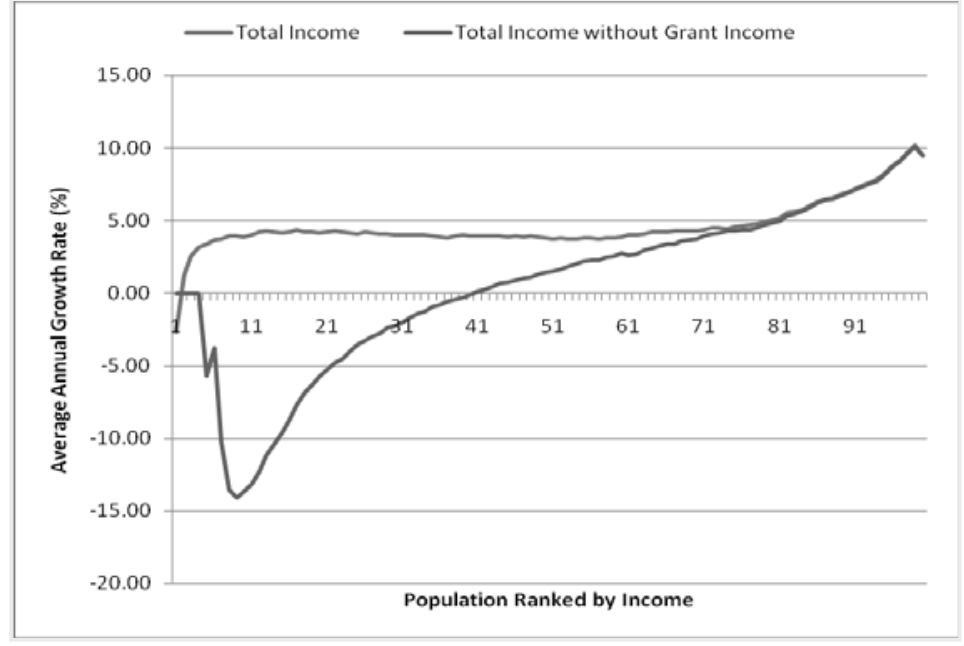

Source: Statistics South Africa (1995 and 2008) and Own Calculations

Notes: 1 . The population in 1995 has been weighted according to the 1996 Census, while the population in 2005 has been weighted according to the 2001 Census. In both datasets, the population has been weighted by the household weight multiplied by the household size.

2. Figures are annualised growth rates

Again, those at the top end of the distribution benefit most from economic growth as captured by the upward sloping GIC when grant income is excluded. In fact, from the 80th percentile upward, the exclusion of grant income does not appear to substantially alter the growth rates. 
Figure 19 presents the GICs for the African population and the pattern is similar to that at national level. The GIC for Africans calculated for total income without grant income, shows that without grant income, individuals at the bottom end of the distribution would have experienced negative growth in income over the period. The average annual growth rate only becomes positive for those individuals from the 50th percentile, and then increases steadily, showing that once more most of the growth in income would have occurred at the very top of the distribution. Again, in the absence of the provision of grant income, growth would not have been pro-poor in the absolute or relative sense. In addition, the mean of the growth rates (not shown here) is very close to zero.

Figure 19: Growth Incidence Curve for Africans - Household Income without Grants, 1995 - 2005

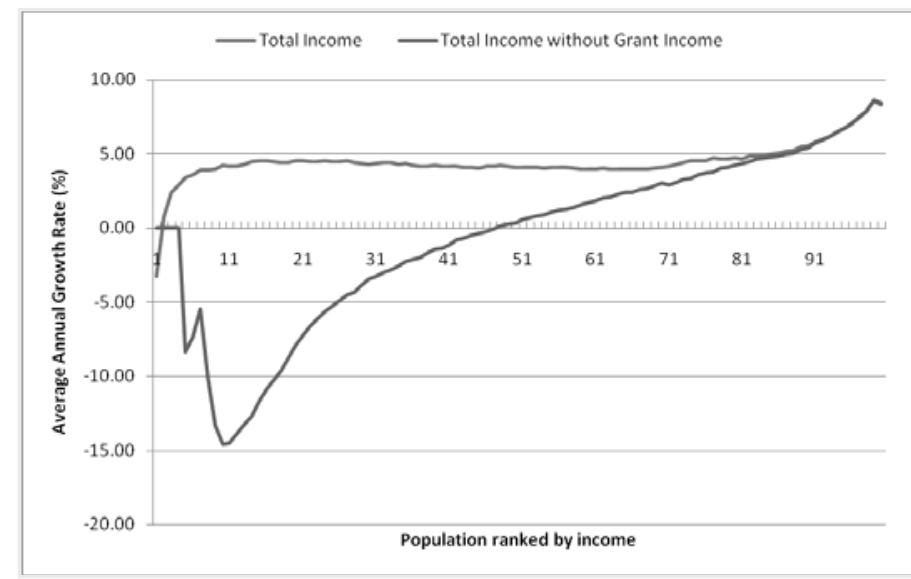

Source: Statistics South Africa (1995 and 2008) and Own Calculations

Notes: 1 . The population in 1995 has been weighted according to the 1996 Census, while the population in 2005 has been weighted according to the 2001 Census. In both datasets, the population has been weighted by the household weight multiplied by the household size.

2. Figures are annualised growth rates

The graph in Appendix 14 further illustrates the importance of social grants as a source of income for the African population. In 2005, grant income accounted for more than 50 percent of total income for individuals in the bottom four income deciles and even up to the seventh decile grant income was a significant source of income for this population group.

Excluding grant income from total income does not affect all the races equally (the GIC for the other race groups are presented in Appendix 13). While no pro-poor growth occurs when grant income is excluded from total income, the impact is less adverse for the Coloured population group. Only a small share of individuals at the bottom distribution displays a negative growth rate. The mean growth rate for the Coloured population is higher than the mean growth rate for the African population when grant income is excluded from total income. In addition, the 
average annual growth rate becomes positive from around the 15th percentile for the Coloured population, compared to the 50th percentile for the African population.

Grant income also plays a particularly important role for individuals living in rural households. The GIC in Figure 20 shows that in the absence of grant income, individuals up to the 70th percentile would have experienced a decline in their incomes between 1995 and 2005.

Figure 20 Growth Incidence Curves for Rural Households - Household Income without Grants, 1995-2005

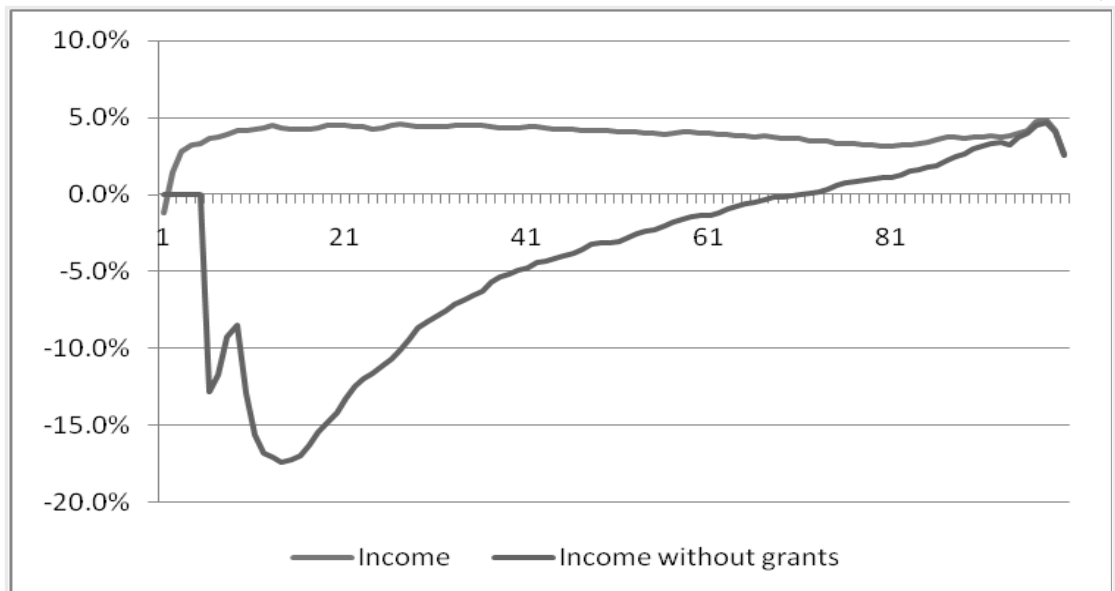

Source: Statistics South Africa (1995 and 2008) and Own Calculations

Notes: 1 . The population in 1995 has been weighted according to the 1996 Census, while the population in 2005 has been weighted according to the 2001 Census. In both datasets, the population has been weighted by the household weight multiplied by the household size.

2. Figures are annualised growth rates

The results above suggest that government's provision of social grants has been an extremely important source of income support to poor households in rural areas. Table 18 compares the pro-poor growth rate both when grant income is excluded and included for South Africa and for rural areas. These numbers reinforce the fact that in the absence of grant income, individuals at the bottom of the distribution would have experienced a decline in income over the period. 
Table 18: Rate of Pro-poor growth excluding Grant Income, 1995-2005

\begin{tabular}{llll}
\multicolumn{3}{c}{ Rate of PPG } \\
\hline & Total Income Including Grants & \multicolumn{2}{c}{ Total Income excluding Grants } \\
& & South Africa \\
10 & 3.85 & -13.66 \\
15 & 4.13 & -9.68 \\
20 & 4.18 & -5.78 \\
25 & 4.12 & & -3.54 \\
30 & 4.01 & -2.23 \\
& & & \\
10 & 4.16 & & -12.86 \\
15 & 4.18 & -17.17 \\
20 & 4.49 & -14.18 \\
30 & 4.31 & & -11.08 \\
\hline
\end{tabular}

Source: $\quad$ Statistics South Africa (1995 and 2008) and Own Calculations

Notes: 1 . The population in 1995 has been weighted according to the 1996 Census, while the population in 2005 has been weighted according to the 2001 Census. In both datasets, the population has been weighted by the household weight multiplied by the household size.

2. Figures are annualised growth rates

The results also confirm the critical role of the provision of social grants in rural areas. The growth rates at the aggregate and for rural areas are quite similar when total income, including grants, is considered. In the absence of social grants, the rural poor would have experienced much more severe negative growth rates than the country as a whole. This result reflects the significance of social grants in the government's fight against poverty and inequality in rural areas, which generally have higher unemployment rates and more limited employment opportunities than urban areas.

Below we attempt to attribute a value to the consumer loss experienced by individuals when grant income is excluded from total income, by estimating the area between the two GICs (GIC including and excluding grant income). We do this for the aggregate level, as well as for the African population and for individuals living in rural areas. 
Since the functional form of the GIC is unknown, we use the definite integral method to estimate the area below both curves. This involves:

$A_{\text {GIC }}=\sum_{k=1}^{n} f\left(u_{k}\right) \Delta x, \quad$ where $f\left(u_{k}\right)$ is the minimum value of $f$ on $\left[x_{k-1}, x_{k}\right]$

Once the areas below both curves are known, we subtract the two values from each other in order to estimate the area between the two curves. This would enable us to estimate the value of the income loss experienced by individuals in units. Despite the fact that the value capturing the income loss is not immediately comprehensible, the values can be compared with one another, and thus provide us with some clues about the stratum of the population which is most affected by grant income.

Table 19: Income loss when Grant Income is excluded from Total Income, 1995-2005

\begin{tabular}{lc}
\cline { 2 - 2 } & Income Loss Area \\
\hline African Population & 508.9 \\
Rural Areas & 767.2 \\
Aggregate & 411.2 \\
\hline
\end{tabular}

Source: Statistics South Africa (1995 and 2008) and Own Calculations

Notes: 1. The population in 1995 has been weighted according to the 1996 Census, while the population in 2005 has been weighted according to the 2001 Census. In both datasets, the population has been weighted by the household weight multiplied by the household size.

The evidence presented in table 19 reinforces the importance of grant income to individuals across South Africa. Without grant income, the income area loss would range from 411.2 units in South Africa as a whole to 767.2 units in rural areas. Grant income therefore makes the biggest difference to those individuals residing in rural areas, followed by African individuals. The income loss area for those in rural areas is almost double that of South Africa as a whole.

The value of the area of income lost is not an intuitive one, to remedy this, we consider the rand value of income lost if grant income was excluded as a source of income. The rand value is calculated by subtracting the difference in total income between 1995 and 2005 by the difference in total income excluding grant income between 1995 and 2005. 


$$
\begin{array}{rlr}
\text { Potential Income Loss } & =\sum_{i=1}^{100}\left[\left(Y_{05}^{T}-Y_{95}^{T}\right)-\left(Y_{05}^{N G}-Y_{95}^{N G}\right)\right] i \\
& =\sum_{i=1}^{100}\left[\left(Y_{05}^{N G}+Y_{05}^{G}-Y_{95}^{N G}-Y_{95}^{G}\right)-\left(Y_{05}^{N G}-Y_{95}^{N G}\right)\right]_{i} \\
& =\sum_{i=1}^{100}\left[\left(Y_{05}^{G}-Y_{95}^{G}\right)\right]_{i} & 1 \leq / \leq 100
\end{array}
$$

where $Y^{T}=Y_{t}^{N G}+Y_{t}^{G}$ and $Y^{T}$ is the total income in period $\mathrm{t}$; $Y_{t}^{N G}$ is the total income excluding grant income, $Y_{t}^{G}$ is the income from state transfers and $\mathrm{i}$ is each percentile.

Table 20 presents the result at the aggregate as well as for the African population and individuals living in rural areas. These suggest that if grant income was excluded from total income, the potential loss in income experienced at the aggregate level would have been more than R43 billion. The African population would have experienced a loss of almost R35 billion, while those living in rural areas would have experienced a loss of about R22 billion. Table 20 also provides an indication of the share of this potential loss of income in GDP, total fiscal

\begin{tabular}{|c|c|c|c|}
\hline \multicolumn{4}{|c|}{ Potential Income Loss } \\
\hline & & Units(squared) & Rand Value \\
\hline \multicolumn{2}{|l|}{ African } & 508.9 & $34,867,174,366$ \\
\hline \multicolumn{2}{|l|}{ Rural } & 767.2 & $21,716,204,376$ \\
\hline \multicolumn{2}{|l|}{ Aggregate } & 411.2 & $43,264,527,669$ \\
\hline & $\%$ of Revised GDP & $\%$ of Total Fiscal Expenditure & $\%$ of Total Grant Expenditure \\
\hline African & 2.26 & 8.01 & 67.15 \\
\hline Rural & 1.41 & 4.99 & 41.82 \\
\hline Aggregate & 2.80 & 9.94 & 83.32 \\
\hline & \multicolumn{3}{|c|}{ Statistics South Africa (1995 and 2008); National Treasury and Own Calculations } \\
\hline Notes: & $\begin{array}{l}\text { The population in } 1995 \text { has be } \\
\text { population in } 2005 \text { has been } v \\
\text { been weighted by the househ }\end{array}$ & $\begin{array}{l}\text { according to the } 1996 \text { Census, while the } \\
\text { rding to the } 2001 \text { Census. In both datase } \\
\text { tiplied by the household size. }\end{array}$ & the population has \\
\hline
\end{tabular}
expenditure and total grant expenditure.

Table 20 Potential Loss of Income if Grant Income is Excluded from Total Income 
The importance of grant income, especially for individuals residing in rural areas, raises many questions around the policy options available in the fight against the impact of rising inequality. The rate at which grants are rolled out is unsustainable, and it would be imprudent for the state to increase the number of grant beneficiaries at the same rate as in the past. The state should consider implementing complimentary policy measures to the roll out of grant income, such as strengthening labour market policies and the education system. This would make it easier for labour market entrants to secure employment which would make it easier to wean the South African society off the social security system that we so desperately depend on. 


\section{Conclusion}

The results from the paper confirm the perception that South Africa is one the most unequal societies in the world. The shifts in income inequality were dramatic to say the least. Income inequality increased significantly between 1995 and 2005, irrespective of race, gender of household head and location. An unexpected result was that income inequality between race groups, rather than income inequality within race groups was the leading cause of the increasing levels of income inequality. The result was unexpected, since previous research using data from a shorter time period, suggested that it was income inequality within race groups (driven by higher levels of African inequality) that was causing the increase in income inequality.

To find the reason behind the burgeoning income inequality, we decomposed the Gini coefficient by income sources. The evidence points to wage income as the main contributor to income inequality. Not only did wage income remain the driver of total income inequality, but its contribution to income inequality increased over the period. The increasing levels of wage inequality were mainly explained by the increasing wage differential between the 90th and 50th percentiles, rather than the wage differential between the top and bottom of the wage income distribution. The increasing gap in wages between the 90th and 50th percentiles can partly be explained the ever-increasing skill premium paid to highly skilled workers.

Interestingly, though, the share of income inequality explained by income from selfemployment decreased in the period under review. In other words, while remaining positive, the contribution of income from self-employment to total income inequality decreased between 1995 and 2005. While the suspicion remains that the increasing share of self employment income in the lower income deciles may largely be a reflection of improved capturing of this type of income by the 2005 survey, this result does highlight the potential of the promotion of self-employment as intervention aimed at alleviating income inequality.

For a more holistic view of inequality we also considered changes in non-income inequality and an index of public and private assets was created to enable us to measure this. Even though income inequality increased significantly between 1995 and 2005, we find that there was an overall decrease in non-income inequality, irrespective of race, gender of household head and province. Whilst non-income inequality decreased, many households, especially at the bottom end of the distribution, remain without access to basic services such as running 
water, sanitation and electricity, highlighting the important role government still has to play in the further provision of basic services.

The GIC for South Africa shows that economic growth in South Africa did not benefit the rich and poor equally. Even though growth in South Africa was pro-poor in the absolute sense, economic growth benefitted the top end of distribution more than the bottom of the distribution. The GIC for South Africa is upward-sloping which indicates that income inequality has increased, confirming the results of the measures of income inequality. The GIC for the African population, urban and rural areas, and male- and female-headed households exhibit a similar trend, with absolute pro-poor growth being present across sub-groups. The experience of individuals living in rural areas was somewhat different to that of individuals living in urban areas, as most of the individuals at the bottom of the rural income distribution experienced greater levels of economic growth than the rest of the distribution.

We also find that most of the potential poverty gains of economic growth was eroded by the rising levels of income inequality within South Africa. In addition, economic growth became less pro-poor over time. Higher growth rates are therefore needed to compensate for the rising inequality. It is unlikely that South Africa would be able to sustain higher growth rates, and so alternative policies are needed which would aid poverty reduction. One such policy that the South African Government has successfully implemented is the increased provision of social grants. Not only did more individuals have access to grant income, but grant income also accounted for a greater proportion of total income over time. The increased provision of grant income has helped to suppress the increase in income inequality as shown by the large differences in the Gini coefficient and the GIC curve, when grant income is included and excluded as a source of income. This is especially true for individuals living in rural areas, as their heavy reliance on grant income explains why rural areas were better off than their urban counterparts when their GICs including grant income were compared. It was grant income that provided the poor with the means to have such a positive growth experience. Without grant income as a source of income, many households across the distribution would have experienced negative growth, and there would be no pro-poor growth, not even in its weakest form. The African population and individuals living in rural areas would be most affected in the absence of increase provision of state transfers. While appearing to be an effective policy too in at least limiting the increase of income inequality, large scale expansion of the social security net is not a viable policy option, highlighting the importance of other policy interventions particularly aimed at job creation for the poor and the unskilled. 


\section{Bibliography}

Bhorat, H. \& Oosthuizen, M. 2006. Evolution of the Labour Market: 1995-2002. In: Bhorat \& Kanbur R (eds) Poverty and Policy in Post-Apartheid South Africa. HSRC Press, Cape Town, pp. 143-193.

Bhorat, H. \& Goga, S. 2008. Wage Formation and Wage Trends in South Africa. pp. 1 - 42. Development Policy Research Unit, Cape Town

Bhorat, H. \& Van der Westhuizen, C. 2007. Economic Growth, Poverty and Inequality in South Africa: The First Decade of Democracy. Development Policy Research Unit

Bhorat, H., Van der Westhuizen, C. \& Goga, S. 2007. Welfare Shifts in the Post-apartheid South Africa: A Comprehensive Measurement of Changes. pp. 1-51. Development Policy Research Unit

Casale, D. \& Posel, D. 2002. The Continued Feminisation of the Labour Force in South Africa: an Analysis of Recent Data and Trends. South African Journal of Economics 70, 156-184

Datt, G. \& Ravallion, M. 1992. Growth and Redistribution Components of Changes in Poverty Measures. Journal of Development Economics. 38. pp. 275-295.

Essop, H. \& Yu, D. 2008. The South African Informal Sector (1997-2006). In: The Regulatory Environment and its Impact on the Nature and Level of Economic Growth and Development in South Africa, pp. 1-58, Glenburn Lodge, Muldersdrift, South Africa

Fields, G.S. 2001. Distribution and Development: A New Look at the Developing World. New York: Russel Sage Foundation.

Hoogeveen, J.G. \& Özler, B. 2006. Poverty and Inequality in Post-Apartheid South Africa: 19952000. In: Bhorat H \& Kanbur R (eds) Poverty and Policy in Post-Apartheid South Africa. HSRC Press, Cape Town, pp. 59-94.

Kakwani, N. 1993. Poverty and Economic Growth with Application to Côte D'Ivoire, Review of Income and Wealth, 39 (2) June 1993.

Kanbur, R. 2005. Growth, Inequality and Poverty: Some Hard Questions. Journal of International Affairs Spring 
Leibbrandt, M., Levinsohn, J. \& McCrary, J. 2005. Incomes in South Africa since the Fall of Apartheid. NBER Working Paper No. 11384

Leibbrandt, M., Poswell, L., Naidoo, P. \& Welch, M. 2006. Measuring Recent Changes in South African Inequality and Poverty using 1996 and 2001 Census Data. In: Kanbur R \& Bhorat H (eds.) Poverty and Policy in Post Apartheid South Africa. HSRC Press, Cape Town.

Leibbrandt, M., Woolard, I. \& Bhorat, H. 2001. Understanding Contemporary Household Inequality in South Africa. In: Bhorat et al, Fighting Poverty: Labour Markets and Inequality in South Africa. HSRC Press, Cape Town, pp. 21-40.

Leibbrandt, M., Woolard, I. 2005 Towards a Poverty Line for South Africa: Background Note. Available from www.treasury.gov.za

Lerman, R.I. \& Yitzhaki, S. 1985. Income Inequality Effects by Income Source: A New Approach and Applications to the United States. The Review of Economics and Statistics 1, 151-156

National Treasury. 2005. Budget Speech 2005. 25 February 200_. Available from www.treasury. gov.za

Oosthuizen, M. 2006. The Post-Apartheid Labour Market: 1995-2004. Working Paper 06/103, pp. 1-65. Development Policy Research Unit

Oosthuizen, M. \& Naidoo, P. 2004. Internal Migration to the Gauteng Province. Development Policy Research Unit Working Paper 04/88, 1-50

Pauw, K. \& Mncube, L. 2007. Expanding the Social Security Net in South Africa: Opportunities, Challenges and Constraints. DPRU Working Paper 07/127. Development Policy Research Unit

Posel, D. \& Casale, D. 2006. Internal Migration and Household Poverty in Post-Apartheid South Africa. In: Kanbur R \& Bhorat H (eds) Poverty and Policy in Post Apartheid South Africa. HSRC Press, Cape Town.

Ravallion, M. 2001. Growth, Inequality and Poverty: Looking Beyond Averages. World Development 29, 1803-1815 
Ravallion, M. \& Chen, S. 2003. Measuring Pro-Poor Growth. Economic Letters 78, 93-99

Sen, A. 1997. On Economic Inequality. Clarendon Press: Oxford

Swokowski, E.W. 1992. Integrals. Calculus. PWS-KENT, United States of America, pp. 201-261.

Van der Westhuizen, C., Goga, S. \& Oosthuizen, M. 2007. Women in the South African Labour Market 1995-2005. DPRU Working Paper 07/118, 1-50 


\begin{tabular}{lcc} 
Appendix 1: & $\begin{array}{c}\text { Annual Mean Per Capita Household Income by Income } \\
\text { Decile }\end{array}$ & \multicolumn{2}{c}{ Total Household Income Per Capita } \\
\hline & 1995 & 2005 \\
Decile 1 & 710 & 967 \\
Decile 2 & 1212 & 1818 \\
Decile 3 & 1688 & 2527 \\
Decile 4 & 2262 & 3340 \\
Decile 5 & 3014 & 4419 \\
Decile 6 & 4131 & 5992 \\
Decile 7 & 5830 & 8826 \\
Decile 8 & 8942 & 14136 \\
Decile 9 & 15598 & 28579 \\
Decile 10 & 46124 & 110111 \\
& & 18066 \\
\hline Total & 8941 & \\
\hline
\end{tabular}

Source: Statistics South Africa (1995 and 2008) and Own Calculations

\section{Appendix 2: Inequality Shifts by Province: Gini Coefficients for South Africa, 1995 and 2005}

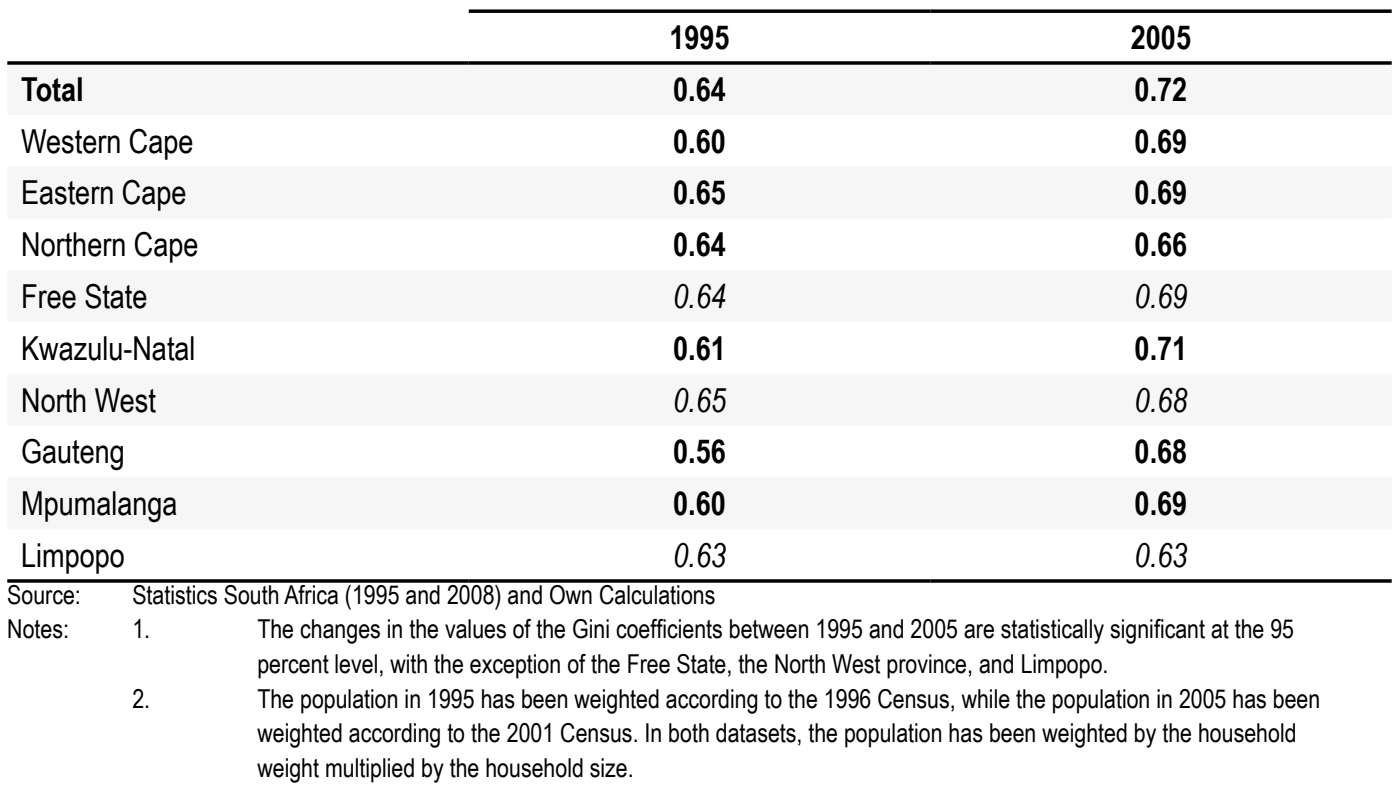




\section{Appendix 3: Theil Index by Province for South Africa, 1995-2005}

\begin{tabular}{|c|c|c|c|c|}
\hline \multirow[t]{2}{*}{ Province } & \multicolumn{4}{|c|}{ South Africa } \\
\hline & & & & \\
\hline All (total) & 0.87 & & 1.14 & \\
\hline Within & 0.77 & $88.4 \%$ & 1.02 & $89.2 \%$ \\
\hline Between & 0.10 & $11.6 \%$ & 0.12 & $10.8 \%$ \\
\hline
\end{tabular}

Source: $\quad$ Statistics South Africa (1995 and 2008) and Own Calculations

Notes: We are unable to calculate t-statistics and confidence intervals for the Theil Index and therefore unable to comment on the statistical significance of the changes between 1995 and 2005 in the Theil Index.

\section{Appendix 4: Theil Index Gender of Household Head South Africa, $1995-2005$}

\section{Appendix 5: Shifts in the Urban and Rural population South Africa, 1995-2005}

\begin{tabular}{llcc}
\hline & 1995 & $\mathbf{2 0 0 5}$ & Average Annual Growth Rate \\
\hline Urban Area & $20,007,096$ & $27,951,500$ & $3.4 \%$ \\
Rural Area & $18,213,800$ & $19,438,972$ & $0.7 \%$ \\
Total & $38,220,896$ & $47,390,472$ & $2.2 \%$ \\
\hline
\end{tabular}

Source: Statistics South Africa (1995 and 2008) and Own Calculations 


\section{Appendix 6: The Composition of State Transfers and "Other" Income}

State transfers in 1995 include: Old Age Pension; Disability grants and Family, other allowances, maintenance while other income include: Workmen's Compensation, Unemployment; Income from sidelines; Income from sale of vehicles; Income from sale of property ; Income from sale of goods ; Payments from boarders; Value of company housing; Value of company transport; Value of pension funds, etc ; Value of other company benefits ; Value of lump sum payments from employer ; Value of endowment policies ; Workmen's compensation payouts; Life insurance payouts, inheritances ; Funeral fund claims ; Claims from property damage ; Claims from road accident funds; Income from other gratuities ; Stokvel claims ; Withdrawal from savings; Income from bursaries ; Income from cash donations ; Value of food received;Value of housing received; Value of clothing received; Value of other donations received; Lobola/dowry received; All other income; All other income not elsewhere shown; Total income ; Tax refunds.

In 2005 State transfers include Old Age Grants, Disability Grants and Child Support Grants while Other income include: Income received from Hobbies; Sidelines \& part-time activities; Sale of vehicle, property etc; Payments from boarders \& other non-members; Goods \& services by virtue of occupation; Claims; Stokvel; Non-refundable bursaries; Benefits, donations and gifts; Cash; Value of food received; Value of housing; Value of clothing; Value of transport; Value of other benefits, donations, gifts etc; Lobola or dowry received; Income from gambling; Tax refunds received; Income not elsewhere specified; Gratuities and other lump-sum payments. 


\section{Appendix 7: Gini Decomposition by Income Source for Race groups, 1995-2005}

\section{African Population 1995}

\begin{tabular}{|c|c|c|c|c|c|c|c|c|c|c|c|c|c|c|}
\hline & 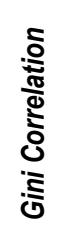 & 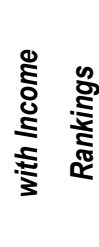 & & 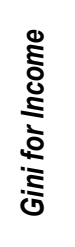 & 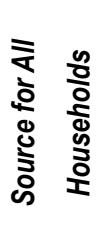 & & 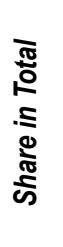 & $\begin{array}{l}\text { §ั } \\
\text { ఏ }\end{array}$ & 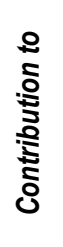 & 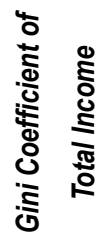 & & 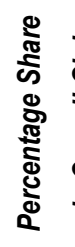 & 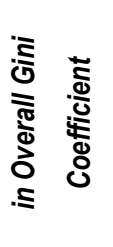 & \\
\hline Income Source & & $\mathbf{R}_{\mathrm{k}}$ & & & $G_{k}$ & & & $S_{k}$ & & $S_{k} G_{k} R_{k}$ & & & Share & \\
\hline Employment & & 0.90 & & & 0.70 & & & 0.64 & & 0.40 & & & $71.8 \%$ & \\
\hline Self-employment & & 0.77 & & & 0.98 & & & 0.08 & & 0.06 & & & $10.6 \%$ & \\
\hline Grants & & -0.08 & & & 0.82 & & & 0.06 & & 0.00 & & & $-0.7 \%$ & \\
\hline Capital & & 0.69 & & & 1.00 & & & 0.00 & & 0.00 & & & $0.5 \%$ & \\
\hline Private pensions & & 0.37 & & & 0.98 & & & 0.01 & & 0.00 & & & $0.8 \%$ & \\
\hline Other & & 0.60 & & & 0.76 & & & 0.21 & & 0.10 & & & $17.1 \%$ & \\
\hline Gini & & & & & & & & & & 0.56 & & & $100.0 \%$ & \\
\hline \multicolumn{15}{|c|}{ African Population 2005} \\
\hline & $\overline{\mathrm{E}}$ & 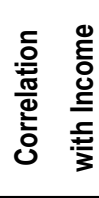 & 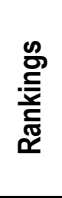 & 高 & 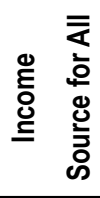 & $\begin{array}{l}\text { 응 } \\
\frac{0}{0} \\
\frac{0}{\Phi} \\
\stackrel{0}{0} \\
\text { 오 }\end{array}$ & 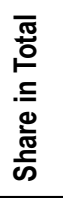 & 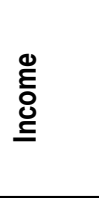 & 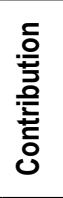 & 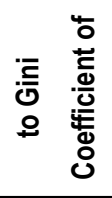 & 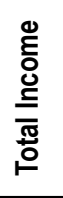 & 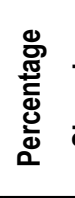 & 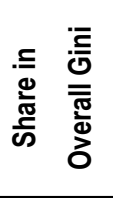 & 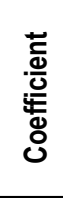 \\
\hline Income Source & & $\mathbf{R}_{\mathrm{k}}$ & & & $G_{k}$ & & & $\mathrm{~S}_{\mathrm{k}}$ & & $S_{k} G_{k} R_{k}$ & & & Share & \\
\hline Employment & & 0.94 & & & 0.79 & & & 0.68 & & 0.51 & & & $83.1 \%$ & \\
\hline Self-employment & & 0.70 & & & 0.95 & & & 0.08 & & 0.05 & & & $8.8 \%$ & \\
\hline Grants & & 0.00 & & & 0.63 & & & 0.13 & & 0.00 & & & $0.0 \%$ & \\
\hline Capital & & 0.72 & & & 1.00 & & & 0.01 & & 0.00 & & & $0.7 \%$ & \\
\hline Private pensions & & 0.54 & & & 0.98 & & & 0.01 & & 0.01 & & & $1.0 \%$ & \\
\hline Other & & 0.53 & & & 0.84 & & & 0.09 & & 0.04 & & & $6.4 \%$ & \\
\hline Gini & & & & & & & & & & 0.61 & & & $100.0 \%$ & \\
\hline
\end{tabular}




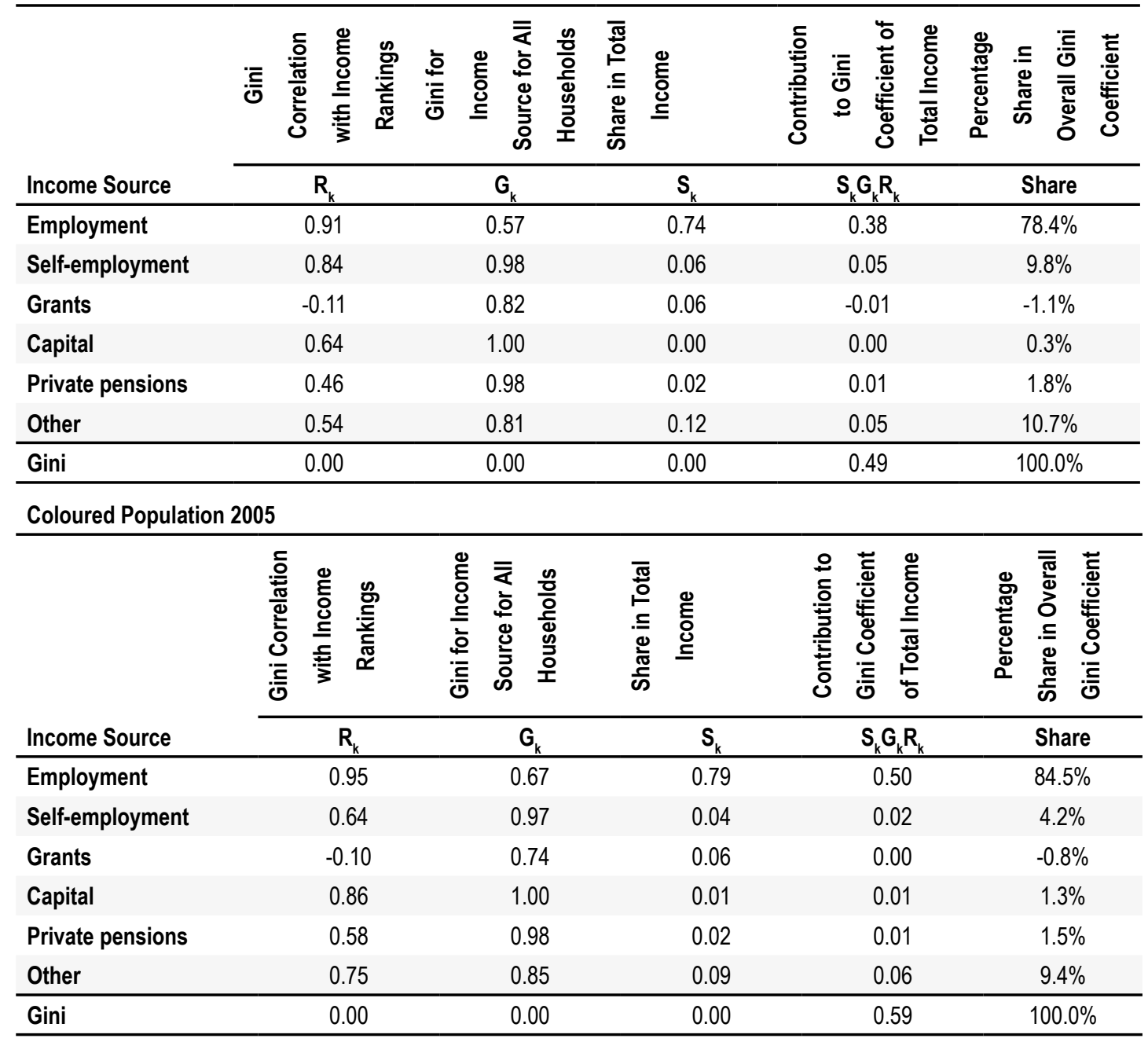


White Population 1995

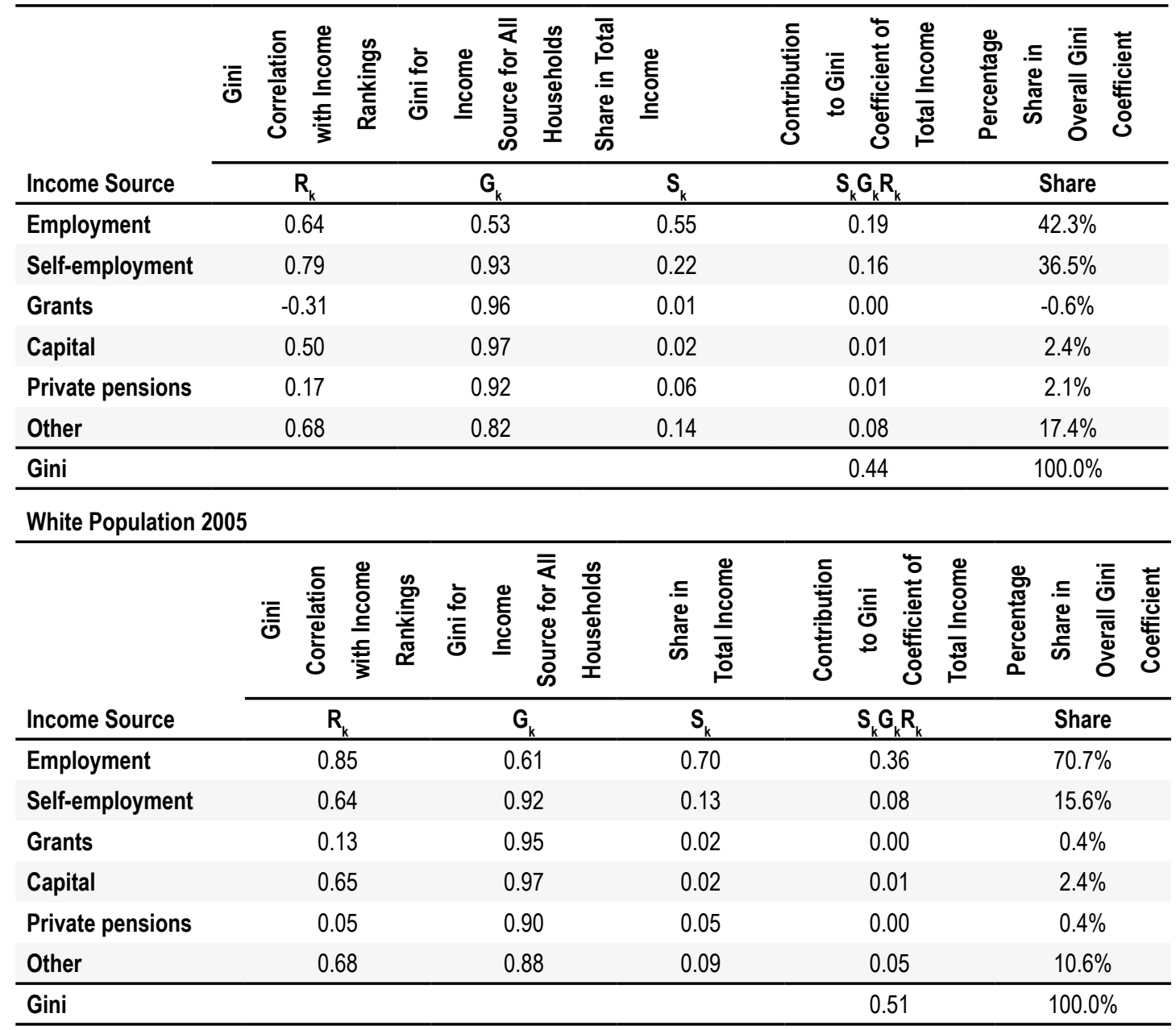




\begin{tabular}{|c|c|c|c|c|c|c|c|c|c|c|c|c|c|c|c|}
\hline & $\overline{\mathrm{O}}$ & 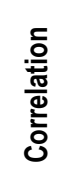 & 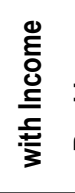 & 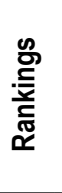 & 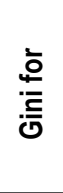 & 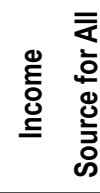 & 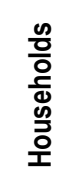 & 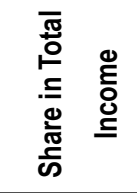 & 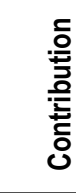 & $\begin{array}{l}\bar{E} \\
0 \\
\end{array}$ & 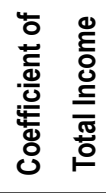 & 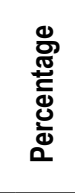 & $=$ & 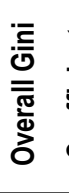 & 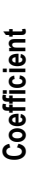 \\
\hline Income Source & \multicolumn{4}{|c|}{$\mathbf{R}_{\mathrm{k}}$} & \multicolumn{3}{|c|}{$G_{k}$} & $S_{k}$ & \multicolumn{3}{|c|}{$S_{k} G_{k} R_{k}$} & \multicolumn{4}{|c|}{ Share } \\
\hline Employment & \multicolumn{4}{|c|}{0.71} & \multicolumn{3}{|c|}{0.51} & 0.59 & \multicolumn{3}{|c|}{0.21} & \multicolumn{4}{|c|}{$46.1 \%$} \\
\hline Self-employment & \multicolumn{4}{|c|}{0.77} & \multicolumn{3}{|c|}{0.91} & 0.23 & \multicolumn{3}{|c|}{0.16} & \multicolumn{4}{|c|}{$34.1 \%$} \\
\hline Grants & \multicolumn{4}{|c|}{-0.38} & \multicolumn{3}{|c|}{0.88} & 0.02 & \multicolumn{3}{|c|}{-0.01} & \multicolumn{4}{|c|}{$-1.3 \%$} \\
\hline Capital & \multicolumn{4}{|c|}{0.51} & \multicolumn{3}{|c|}{0.98} & 0.01 & \multicolumn{3}{|c|}{0.01} & \multicolumn{4}{|c|}{$1.2 \%$} \\
\hline Private pensions & \multicolumn{4}{|c|}{0.48} & \multicolumn{3}{|c|}{0.98} & 0.01 & \multicolumn{3}{|c|}{0.01} & \multicolumn{4}{|c|}{$1.5 \%$} \\
\hline Other & \multicolumn{4}{|c|}{0.72} & \multicolumn{3}{|c|}{0.84} & 0.14 & & 0.0 & 08 & & $18.3^{\circ}$ & & \\
\hline Gini & & 0.0 & 00 & & & 0.00 & & 0.00 & & 0.4 & 46 & & 100.0 & $0 \%$ & \\
\hline Asian Population & & & & & & & & & & & & & & & \\
\hline & $\overline{\mathrm{E}}$ & 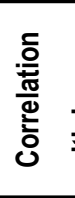 & 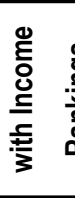 & 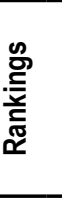 & 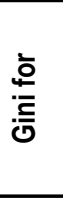 & 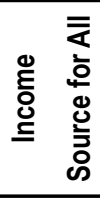 & $\begin{array}{l}\text { 응 } \\
\text { 응 } \\
\stackrel{心}{0} \\
\text { 오 }\end{array}$ & 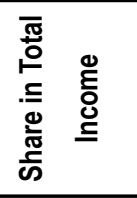 & 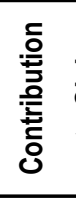 & 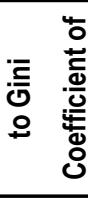 & 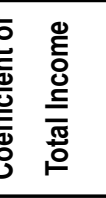 & 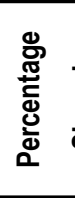 & 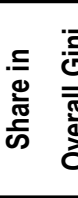 & 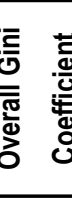 & טֶّ \\
\hline Income Source & & $\mathrm{R}_{\mathrm{k}}$ & & & & $G_{k}$ & & $S_{k}$ & & $S_{k} G_{k} R_{k}$ & & & Share & & \\
\hline Employment & & 0.91 & & & & 0.63 & & 0.74 & & 0.43 & & & $76.2 \%$ & & \\
\hline Self-employment & & 0.75 & & & & 0.94 & & 0.16 & & 0.11 & & & $19.8 \%$ & & \\
\hline Grants & & -0.3 & & & & 0.80 & & 0.03 & & -0.01 & & & $-1.6 \%$ & & \\
\hline Capital & & 0.51 & & & & 0.99 & & 0.01 & & 0.00 & & & $0.7 \%$ & & \\
\hline Private pensions & & 0.52 & & & & 0.98 & & 0.01 & & 0.01 & & & $1.3 \%$ & & \\
\hline Other & & 0.51 & & & & 0.88 & & 0.04 & & 0.02 & & & $3.5 \%$ & & \\
\hline Gini & & 0.00 & & & & 0.00 & & 0.00 & & 0.56 & & & $100.0^{\circ}$ & & \\
\hline
\end{tabular}

Sources: Statistics South Africa 1995 and 2008; Own Calculations.

Notes: $\quad$ Population weights are not available for the 2005 dataset. The population has been weighted by the household weight multiplied by the household size to obtain the population weights. Both sets of weights are 2001 Census weights. 


\section{Appendix 8: Poverty Shifts by Race, Province and Gender of Household Head}

\begin{tabular}{|c|c|c|c|c|}
\hline \multirow{2}{*}{$\begin{array}{l}\text { Category } \\
\text { Year }\end{array}$} & \multicolumn{2}{|c|}{ Headcount } & \multicolumn{2}{|c|}{ Poverty gap ratio } \\
\hline & 1995 & 2005 & 1995 & 2005 \\
\hline \multicolumn{5}{|c|}{ R322 per person per month } \\
\hline African & $51.40 \%$ & $58.91 \%$ & $23.57 \%$ & $28.86 \%$ \\
\hline Coloured & $28.90 \%$ & $30.26 \%$ & $9.94 \%$ & $11.93 \%$ \\
\hline Asian & $3.51 \%$ & $15.05 \%$ & $0.76 \%$ & $6.19 \%$ \\
\hline White & $0.52 \%$ & $1.87 \%$ & $0.15 \%$ & $1.08 \%$ \\
\hline Western Cape & $21.19 \%$ & $25.51 \%$ & $6.88 \%$ & $10.01 \%$ \\
\hline Eastern Cape & $63.86 \%$ & $64.46 \%$ & $32.14 \%$ & $31.28 \%$ \\
\hline Northern Cape & $46.23 \%$ & $56.45 \%$ & $19.27 \%$ & $26.26 \%$ \\
\hline Free State & $55.79 \%$ & $45.70 \%$ & $25.96 \%$ & $20.06 \%$ \\
\hline Kwazulu-Natal & $42.72 \%$ & $60.34 \%$ & $17.95 \%$ & $31.83 \%$ \\
\hline North West & $51.99 \%$ & $50.49 \%$ & $24.53 \%$ & $25.21 \%$ \\
\hline Gauteng & $12.89 \%$ & $28.43 \%$ & $4.23 \%$ & $12.56 \%$ \\
\hline Mpumalanga & $51.93 \%$ & $56.60 \%$ & $22.85 \%$ & $27.23 \%$ \\
\hline Limpopo & $54.40 \%$ & $68.85 \%$ & $26.06 \%$ & $33.77 \%$ \\
\hline Male & $35.41 \%$ & $37.49 \%$ & $15.16 \%$ & $17.22 \%$ \\
\hline Female & $58.08 \%$ & $66.28 \%$ & $27.89 \%$ & $33.33 \%$ \\
\hline Total & $42.58 \%$ & $49.99 \%$ & $19.18 \%$ & $24.22 \%$ \\
\hline \multicolumn{5}{|c|}{$\underline{R} 174$ per person per month } \\
\hline African & $26.91 \%$ & $33.49 \%$ & $9.32 \%$ & $12.79 \%$ \\
\hline Coloured & $8.96 \%$ & $12.00 \%$ & $2.35 \%$ & $4.45 \%$ \\
\hline Asian & $0.27 \%$ & $5.93 \%$ & $0.02 \%$ & $2.98 \%$ \\
\hline White & $0.08 \%$ & $1.21 \%$ & $0.06 \%$ & $0.58 \%$ \\
\hline Western Cape & $5.92 \%$ & $10.18 \%$ & $1.60 \%$ & $3.65 \%$ \\
\hline Eastern Cape & $38.53 \%$ & $36.57 \%$ & $14.14 \%$ & $13.52 \%$ \\
\hline Northern Cape & $21.44 \%$ & $29.60 \%$ & $6.43 \%$ & $10.81 \%$ \\
\hline Free State & $29.91 \%$ & $20.70 \%$ & $9.38 \%$ & $7.59 \%$ \\
\hline Kwazulu-Natal & $19.22 \%$ & $38.58 \%$ & $6.24 \%$ & $15.57 \%$ \\
\hline North West & $28.79 \%$ & $29.99 \%$ & $9.92 \%$ & $11.50 \%$ \\
\hline Gauteng & $3.64 \%$ & $13.21 \%$ & $1.05 \%$ & $5.27 \%$ \\
\hline Mpumalanga & $25.04 \%$ & $30.64 \%$ & $8.26 \%$ & $11.69 \%$ \\
\hline Limpopo & $30.74 \%$ & $39.57 \%$ & $11.35 \%$ & $14.33 \%$ \\
\hline Male & $16.60 \%$ & $19.09 \%$ & $5.40 \%$ & $7.31 \%$ \\
\hline Female & $32.59 \%$ & $39.38 \%$ & $11.82 \%$ & $15.05 \%$ \\
\hline Total & $21.65 \%$ & $27.91 \%$ & $7.43 \%$ & $10.67 \%$ \\
\hline
\end{tabular}




\section{Appendix 9: Datt-Ravallion Decompositions by Province}

\begin{tabular}{lccc} 
Category & Growth component & Redistribution component & Total change in poverty \\
\hline Poverty Line R322 per month & & & \\
Western Cape & -25.76 & 30.09 & 4.33 \\
Eastern Cape & -23.52 & 24.22 & 0.59 \\
Northern Cape & -16.60 & 26.81 & 10.21 \\
Free State & -35.03 & 24.94 & -10.09 \\
Kwazulu-Natal & -14.90 & 32.52 & 17.62 \\
North West & -25.93 & 24.43 & -1.50 \\
Gauteng & -12.78 & 28.33 & 15.55 \\
Mpumalanga & -27.70 & 32.37 & 4.67 \\
Limpopo & -9.94 & 24.39 & 14.45 \\
Poverty Line R174 per month & & & \\
Western Cape & -15.99 & 20.25 & 4.26 \\
Eastern Cape & -31.23 & 29.27 & -1.96 \\
Northern Cape & -17.35 & 25.50 & 8.15 \\
Free State & -33.47 & 24.25 & -9.21 \\
Kwazulu-Natal & -14.05 & 33.41 & 19.36 \\
North West & -25.60 & 26.81 & 1.20 \\
Gauteng & -8.87 & 18.44 & 9.57 \\
Mpumalanga & -26.21 & 31.81 & 5.60 \\
Limpopo & -12.23 & 21.06 & 8.84 \\
\hline
\end{tabular}

Source: Statistics South Africa (1995 \& 2005) and Own Calculations

Notes: $1 . \quad$ The population in 1995 has been weighted according to the 1996 Census, while the population in 2005 has been weighted according to the 2001 Census. In both datasets, the population has been weighted by the household weight multiplied by the household size.

2. The poverty shifts are based on the headcount measures and the two poverty lines of R322 and R174 respectively.

3. Residual values were zero in all cases 


\section{Appendix 10: GIC by Race groups, 1995-2005}
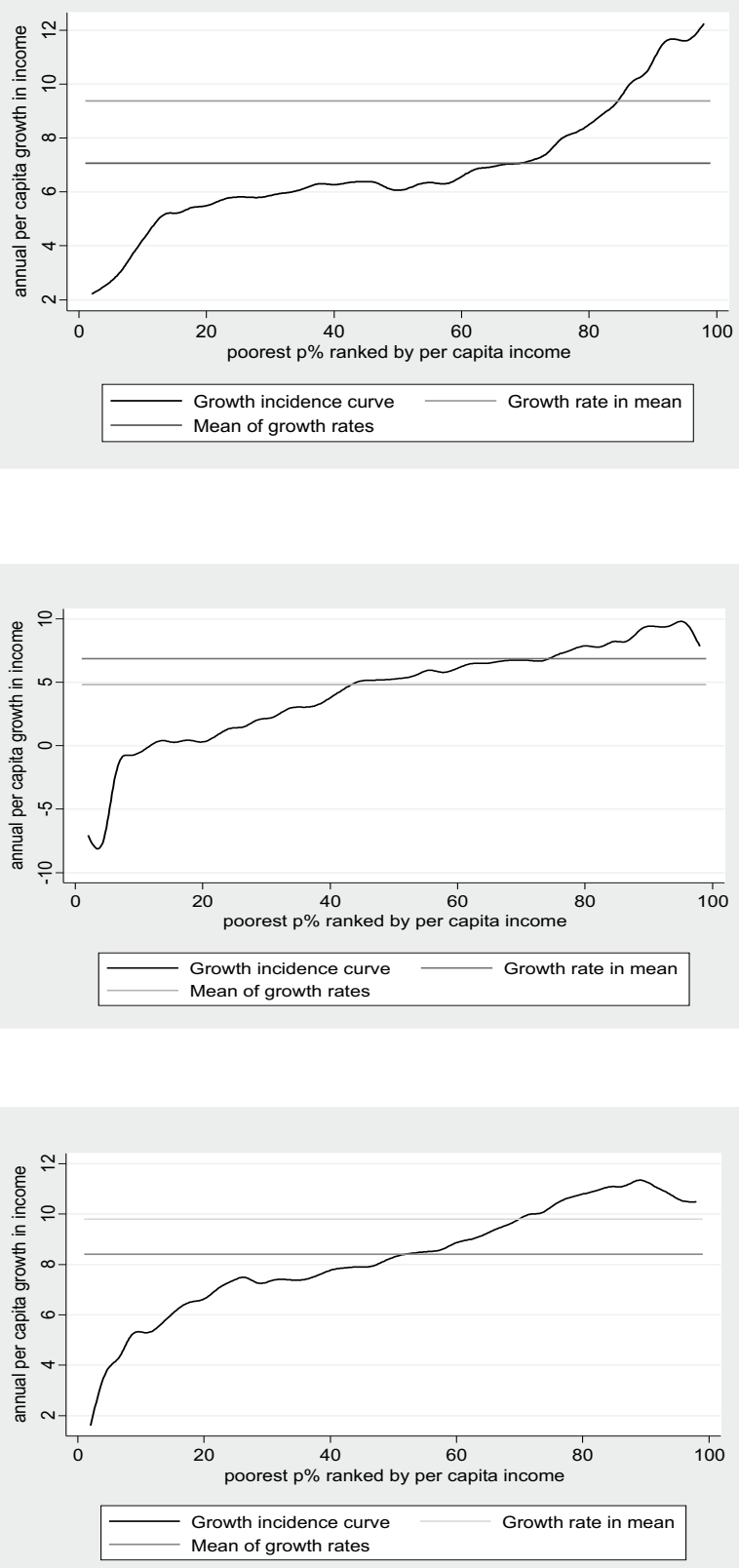

Source: Statistics South Africa (1995 and 2005) and Own Calculations

Notes: $\quad 1$. The population in 1995 has been weighted according to the 1996 Census, while the population in 2005 has been weighted according to the 2001 Census. In both datasets, the population has been weighted by the household weight multiplied by the household size.

2. Figures are annualised growth rates 


\section{Appendix 11: Measures of Pro-poor Growth by Gender of Household Head, $1995-2005$}

\begin{tabular}{|l|c|c|c|}
\hline & Total & Male-Headed & Female-Headed \\
\hline Growth rate in mean & 7.29 & 8.44 & 7.45 \\
\hline Growth rate at median & 3.78 & 5.67 & 4 \\
\hline Mean percentile growth rate & 4.76 & 6.16 & 4.9 \\
\hline Rate of pro-poor growth at corresponding percentile & \multicolumn{2}{|l|}{} \\
\hline 10 & 3.1 & 3.27 & 3.85 \\
\hline 15 & 3.47 & 3.83 & 4.19 \\
\hline 20 & 3.66 & 4.16 & 4.37 \\
\hline 25 & 3.77 & 4.38 & 4.46 \\
\hline 30 & 3.82 & 4.54 & 4.51 \\
\hline
\end{tabular}

Source: $\quad$ Statistics South Africa (1995 and 2008) and Own Calculations

Notes: $1 . \quad$ The population in 1995 has been weighted according to the 1996 Census, while the population in 2005 has been weighted according to the 2001 Census. In both datasets, the population has been weighted by the household weight multiplied by the household size. Figures are annualised growth rates 


\begin{tabular}{|c|c|c|c|c|}
\hline \multicolumn{5}{|c|}{$\begin{array}{l}\text { Appendix 12: Gini Coefficient Including and Excluding Grant Income } \\
\text { from Total Income by Province and Gender of Household } \\
\text { Head, 1995-2005 }\end{array}$} \\
\hline & Per capita Income & $\begin{array}{l}\text { Per capita Income } \\
\text { without Grants }\end{array}$ & Per capita Income & $\begin{array}{l}\text { Per capita Income } \\
\text { without Grants }\end{array}$ \\
\hline Province & 1995 & 1995 & 2005 & 2005 \\
\hline Western Cape & 0.6 & 0.62 & 0.69 & 0.72 \\
\hline Eastern Cape & 0.65 & 0.73 & 0.69 & 0.80 \\
\hline Northern Cape & 0.64 & 0.69 & 0.66 & 0.75 \\
\hline Free State & 0.64 & 0.68 & 0.69 & 0.75 \\
\hline Kwazulu-Natal & 0.61 & 0.65 & 0.71 & 0.79 \\
\hline North West & 0.65 & 0.68 & 0.68 & 0.74 \\
\hline Gauteng & 0.56 & 0.57 & 0.68 & 0.70 \\
\hline Mpumalanga & 0.6 & 0.63 & 0.69 & 0.77 \\
\hline Limpopo & 0.63 & 0.69 & 0.63 & 0.77 \\
\hline \multicolumn{5}{|c|}{ Gender of Household Head } \\
\hline Male & 0.63 & 0.66 & 0.70 & 0.73 \\
\hline Female & 0.59 & 0.66 & 0.68 & 0.80 \\
\hline
\end{tabular}

Source: Statistics South Africa (1995 and 2008) and own calculations

Notes: 1. The changes in the Gini coefficient are statistically significant when the results are in "bold"

2. The population in 1995 has been weighted according to the 1996 Census, while the population in 2005 has been weighted according to the 2001 Census. In both datasets, the population has been weighted by the household weight multiplied by the household size. 


\section{Appendix 13: GIC excluding Grant Income by Race group, 1995 - 2005}

\section{Growth Incidence Curve for Coloureds: 1995-2005}

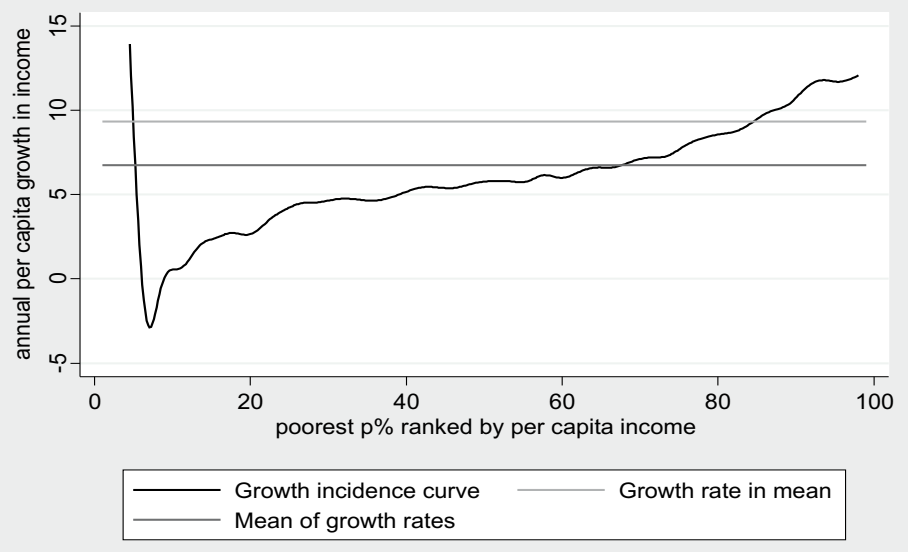

Growth Incidence Curve for Asians: 1995-2005

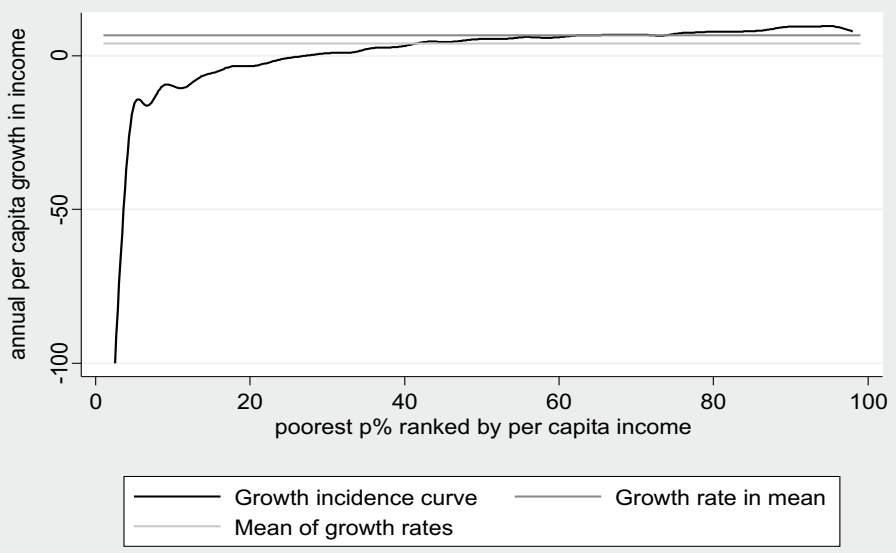




\section{Growth Incidence Curve for Whites: 1995-2005}

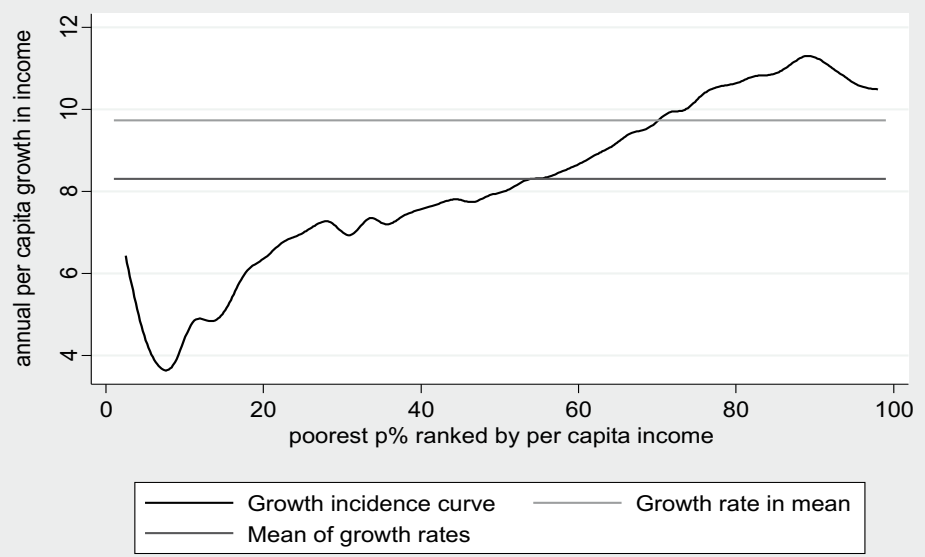

Source: $\quad$ Statistics South Africa (1995 and 2005) and Own Calculations

Notes: $1 . \quad$ The population in 1995 has been weighted according to the 1996 Census, while the population in 2005 has been weighted according to the 2001 Census. In both datasets, the population has been weighted by the household weight multiplied by the household size.

2. Figures are annualised growth rates 


\section{Appendix 14: Per capita Grant Income as a Proportion of Total Household Income for the African Population, 1995- 2005}

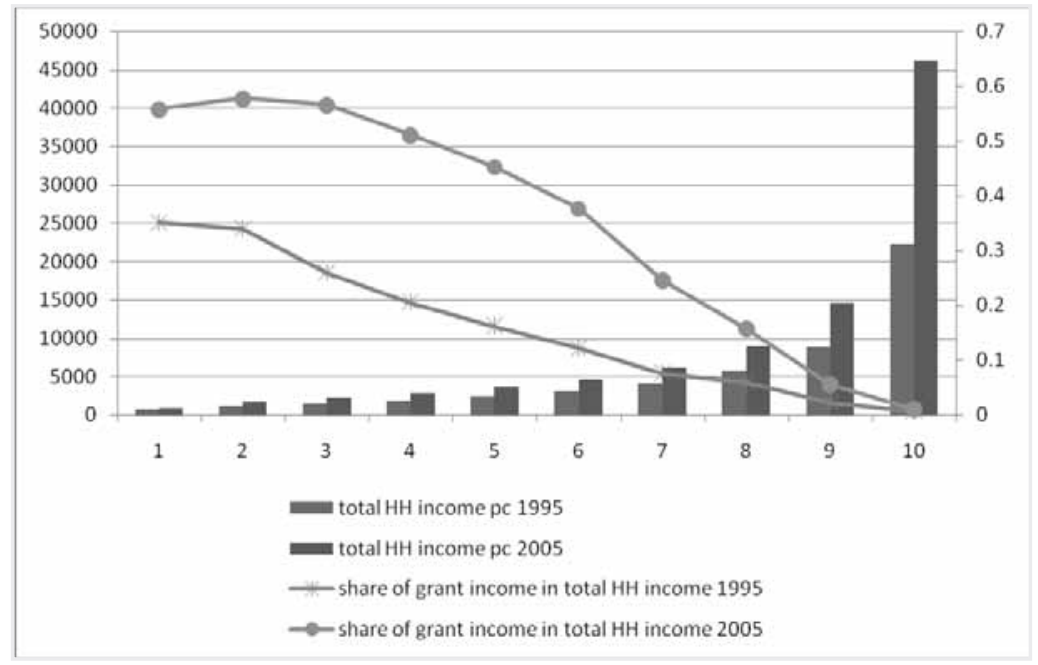

Source: Statistics South Africa (1995 and 2008) and Own Calculations

Notes: $1 . \quad$ The population in 1995 has been weighted according to the 1996 Census, while the population in 2005 has been weighted according to the 2001 Census. In both datasets, the population has been weighted by the household weight multiplied by the household size. 